ఠ

\title{
A fully integrated new paradigm for lithium's mode of action - lithium utilizes latent cellular fail-safe mechanisms
}

This article was published in the following Dove Press journal:

Neuropsychiatric Disease and Treatment

31 January 2017

Number of times this article has been viewed

\author{
Arthur Ernst van Woerkom \\ South Birmingham and Solihull \\ Mental Health NHS Foundation \\ Trust, Longbridge CMHT, Rubery, \\ Birmingham, UK
}

\begin{abstract}
It is proposed that lithium's therapeutic effects occur indirectly by augmenting a cascade of protective "fail-safe" pathways pre-configured to activate in response to a dangerous low cell $\left[\mathrm{Mg}^{++}\right]$situation, eg, posttraumatic brain injury, alongside relative cell adenosine triphosphate depletion. Lithium activates cell protection, as it neatly mimics a lowered intracellular $\left[\mathrm{Mg}^{++}\right]$level.
\end{abstract}

Keywords: lithium, magnesium, GSK-3, traumatic brain injury, inositol, PRPP, valproate, carbamazepine, TRPM-7

\section{Background}

Lithium's strikingly pervasive protective actions provide indirect evidence to support the existence of a set of latent, low cell $\left[\mathrm{Mg}^{++}\right]$-sensitive cell protection systems.

To survive conditions associated with a low cell $\left[\mathrm{Mg}^{++}\right]$, (neuronal) cells would require "fail-safe" mechanisms, as otherwise, below a critically low intracellular $\left[\mathrm{Mg}^{++}\right]$, many $\mathrm{Mg}^{++}$-requiring systems risk grinding to a halt.

This latent vulnerability suggests the existence of protective responses activated by a low intracellular $\left[\mathrm{Mg}^{++}\right]$, which at critical times also appears to function as a metabolic "alarm signal". These systems would help to regulate, buffer, limit, and restore cell $\left[\mathrm{Mg}^{++}\right]$.

$\mathrm{Li}^{+}$therapy has the special advantage of being able to utilize these preexisting systems, as $\mathrm{Li}^{+}$, acting via competition with $\mathrm{Mg}^{++}$, mimics the effects of a lowered cell free $\left[\mathrm{Mg}^{++}\right]$. Augmenting these systems provides lithium's therapeutic effects.

Special conditions of very low intracellular $\left[\mathrm{Mg}^{++}\right]$concentrations can occur.

The system appears configured to optimize neuroprotection against the adverse conditions occurring after traumatic brain injury (TBI), following which the cell $\left[\mathrm{Mg}^{++}\right]$ paradoxically drops to a critically low level.

It is proposed that $\mathrm{Li}^{+}$and a low cell free $\left[\mathrm{Mg}^{++}\right]$both activate the same proposed survival and recovery mechanisms, including the inhibition of the $\mathrm{Li}^{+}$-sensitive, and $\mathrm{Mg}^{++}$-dependent, inositol monophosphatase (IMPase)/inositol polyphosphate 1-phosphatase (IPPase), glycogen synthase kinase 3 (GSK-3), fructose-1,6-bisphosphatase (FBPase), bisphosphate nucleotidase (BPNase), phosphoglucomutase (PGM), adenylate cyclases, certain G-proteins, and beta-arrestin. Cell protection accumulates as cell $\left[\mathrm{Mg}^{++}\right]$levels drop and/or as $\left[\mathrm{Li}^{+}\right]$levels increase.

Inositol depletion represents a more complex sub-mechanism, and in addition to lithium potentially limiting phospholipase C (PLC)-linked receptor systems, inositol 
depletion may exert further protective effects by simultaneously limiting PLC-linked, TRPM7-type membrane PIP2 requiring $\mathrm{Mg}^{++}$-related ion channels.

The "fail-safe model" expands current concepts, as $\mathrm{Li}^{+}$-induced inositol depletion results in "inositol phosphate enhancement"; this sets up a sugar phosphate $\mathrm{Mg}^{++} / \mathrm{Ca}^{++}$ chelation sub-mechanism, adding metal-ion "buffering" as a further regulatory aspect of this group of fail-safe systems, perfectly matched to the specific properties and kinetics of this key family of $\mathrm{Li}^{+}$-sensitive, $\mathrm{Mg}^{++}$-dependent enzymes.

The uncompetitive action of lithium on the IMPase is intrinsically selective.

If, in the relevant disorders, $\mathrm{Li}^{+}$is actually operating in cells with a below-normal cell $\left[\mathrm{Mg}^{++}\right]$level, lithium would then demonstrate an unexpectedly greater selectivity and potency due to these enzymes already rate limited by a low ambient cell $\left[\mathrm{Mg}^{++}\right]$, being still further inhibited by $\mathrm{Li}^{+}$. Statedependent "double inhibition" would help explain lithium's potency and specificity and its apparent lack of activity in normal individuals.

A lowered cell free $\left[\mathrm{Mg}^{++}\right]$concentration itself has the potential to exert a full lithium-like mood-stabilizing action, providing an innate biochemical mechanism for underpinning mental and cellular resilience. These latent fail-safe mechanisms would only become fully operational once the cell $\left[\mathrm{Mg}^{++}\right]$level falls below the system's activation threshold. Lithium would thus expand the operating parameters of the proposed intrinsic "low cell $\left[\mathrm{Mg}^{++}\right]$cell protection system".

Augmentation with $\mathrm{Li}^{+}$would only become required once the system is stressed beyond normal safe-operating limits.

The proposed system utilizes 5-phosphoribosyl-1pyrophosphate (PRibosePP), an important $\mathrm{Mg}^{++}$binding, precursor substrate, linked to nicotinamide adenine dinucleotide $\left(\mathrm{NAD}^{+}\right)$, and linked to maintaining cell [ATP], hence to maintaining normal cell $\left[\mathrm{Mg}^{++}\right]$concentrations.

The emergent "inositol-depletion, ins-phosphate enhancement", "fail-safe paradigm", condenses into a much expanded, unified explanation of the earlier key concepts. This provides unexpected insights into novel mechanisms that appear to underpin mood and related disorders. The corresponding modes of action of valproate and carbamazepine are discussed in outline.

\section{Introduction - existing models}

There are two current, seemingly disconnected, partial theories of lithium's action.

The Berridge "inositol depletion" model ${ }^{1-3}$ proposed that $\mathrm{Li}^{+}$was able to limit (notionally) "excess" signal transduction; as with the proposal here, this was based on the specific properties of certain key enzymes, as $\mathrm{Li}^{+}$inhibits both the IMPase and the related IPPase. .,2,4 $^{2}$

The kinetics of the IMPase appears well matched to the concentration of lithium used. . $^{2,4}$

The more recent GSK-3 theory noted that lithium is capable of exerting a powerful cascade of protective effects by inhibiting the important serine/threonine protein kinase. ${ }^{5}$ The IMPase/IPPase and the GSK-3 enzymes are $\mathrm{Mg}^{++}$ dependent. ${ }^{2,6-8}$ In both these systems, $\mathrm{Li}^{+}$acts via competition with $\mathrm{Mg}^{++}$. 2,6-9

The inositol reversible actions of mood stabilizers do not seem to involve GSK-3 inhibition, inositol-1-phosphate synthase, or inositol transporters, ${ }^{10}$ and the inositol depletion hypothesis is considered to remain, as yet, unproven. ${ }^{11}$ It appears unlikely that lithium's many pervasive effects, eg, on plasticity and survival, ${ }^{12-16}$ can be dismissed, as merely coincidental.

The hydrated ionic radius of $\mathrm{Mg}^{++}$is similar to that of $\mathrm{Li}^{+} .6,9$ It has previously been suggested that competition between $\mathrm{Li}^{+}$ and $\mathrm{Mg}^{++}$ions constitutes the ultimate (molecular) basis for the mechanism of action for $\mathrm{Li}^{+} .{ }^{8,9,16-19}$ Lithium can displace $\mathrm{Mg}^{++}$from some, but not all, binding sites within the (nerve) cell. ${ }^{18}$ Lithium acts as a competitive inhibitor of numerous $\mathrm{Mg}^{++}$-dependent factors, transporters, and enzymes. ${ }^{4}$

\section{A hidden metabolic vulnerability forces the necessity for "low cell $\left[\mathrm{Mg}^{++}\right]$fail- safe mechanisms"? Lithium augments a cellular "protection racket"}

Lithium produces remarkable protective, anti-apoptotic, anti-anoxic, unfolded protein response (UPR), autophagy, cell plasticity, and resilience responses. ${ }^{8,12-15}$

It is proposed that these protective properties ${ }^{8,12,14,15}$ reflect the activity of "fail-safe mechanisms", evolved to protect, maintain, and stabilize function, limit cell injury, and facilitate recovery - (in the critical event of an altered cell [ATP]) associated with a very low (brain) ionized cell free magnesium $\left[\mathrm{Mg}^{++}\right]$level (of the order of $0.2-0.25 \mathrm{mmol} / \mathrm{L}$ ) - as unless some other factor(s) intervenes, below a certain level of low cell free $\left[\mathrm{Mg}^{++}\right]$, hundreds of $\left[\mathrm{Mg}^{++}\right]$-dependent systems (including aspects reliant on $\mathrm{Mg}^{++}$ions for structural reasons) appear at risk of collapsing or grinding to a halt. This predicts the existence of systems to protect cells alongside a critically low cell $\left[\mathrm{Mg}^{++}\right]$contingency and that these may form the basis of lithium's mode of action.

\section{A key family of $\mathbf{M g}^{++}$-dependent and $\mathbf{L i}^{+}$-sensitive phosphatases}

Magnesium has powerful anti-oxidant, anti-necrotic, and anti-apoptotic effects. $\mathrm{Mg}^{++}$is itself broadly cytoprotective, 
cardioprotective, and neuroprotective against a wide range of insults. ${ }^{20}$

The loss of cell protection following a significant drop in cell free $\left[\mathrm{Mg}^{++}\right]$concentration (even if such a decrease were not associated with the probability of occurring alongside other adverse factors) would force the need for compensatory or more specialized cell protection.

It is proposed that the mood-stabilizing and protective effects of lithium are a consequence of lithium and/or a low cell $\left[\mathrm{Mg}^{++}\right]$, progressively activating a usually "dormant" set of latent cellular "fail-safe" protection/repair systems. By displacing $\mathrm{Mg}^{++}$ions at certain critical sites, lithium "imitates" and mimics a "lowered intracellular $\left[\mathrm{Mg}^{++}\right]$level".

The significance of lithium's wide-ranging actions ${ }^{8,12-16}$ needs to be re-interpreted, given the $\mathrm{Mg}^{++}$requirements (in the millimolar) physiological range of key members of an important family of enzymes.

The IMPase, inositol-1-phosphatase, acted on by $\mathrm{Li}^{+2}$, belongs to a group of magnesium-dependent and lithiumsensitive phosphatases; this group includes IPPase, FBPase, and bisphosphate nucleotidase (BPNase) ${ }^{21} \mathrm{Li}^{+}$also inhibits the structurally unrelated PGM. ${ }^{22}$

These enzymes are sensitive to $\mathrm{Li}^{+}$and require $\mathrm{Mg}^{++}$in relevant concentrations. ${ }^{21}$

It is proposed that this family of enzymes, and GSK-3, provides the core of these "fail-safe" sub-mechanisms mobilized as ionized cell free magnesium $\left[\mathrm{Mg}^{++}\right]$drops below the system's activation threshold, determined by the relevant enzymes' kinetics (see "The IMPase and IPPase" section), which are incidentally also further co-activated by lithium.

This may also present regulatory opportunities, as some $\mathrm{Mg}^{++}$-dependent enzymes can continue to function in the absence of $\mathrm{Mg}^{++}, 23,24$ by using alternative cofactors, such as $\mathrm{Mn}^{++}$ions, but there appear to be changes in the properties of such enzymes, ${ }^{23,24}$ if the commonly used $\mathrm{Mg}^{++}$cofactor is substituted.

Mammalian cells maintain free cytosolic $\mathrm{Mg}^{++}$levels usually within the fairly narrow range of $0.5-1.1 \mathrm{mmol} / \mathrm{L} .^{25,26}$ Transport mechanisms and sequestration within cellular organelles contribute to this regulation; the binding of $\mathrm{Mg}^{++}$ to a previously poorly defined system of buffers appears largely responsible for determining the "set point" of this regulation. ${ }^{25-29}$ Brain ATP, which tends to chelate $\mathrm{Mg}^{++}$, is in the range of $\sim 3.0 \mathrm{mmol} / \mathrm{L}^{30}$

$\mathrm{Mg}^{++}$has actions in all the key systems where lithium has also been suspected of exerting its effects - ion channels, ATPases, G-proteins, cAMP, mitochondria, and phospholipids. ${ }^{8,16}$
Magnesium is required to activate some 300 enzymes and is fully integrated into cell function. ${ }^{25-27,31}$

Few clear-cut metabolic disturbances have been unequivocally established in magnesium deficiency; ${ }^{29}$ which might suggest that intracellular $\mathrm{Mg}^{++}$may be specifically "privileged" and cell $\left[\mathrm{Mg}^{++}\right]$may require special buffering regulatory arrangements as part of fail-safe cell protection systems. There appears to be a critical level of central nervous system (CNS) $\left[\mathrm{Mg}^{++}\right]$concentration below which dysfunction appears to occur. ${ }^{32}$

\section{$\mathrm{Mg}^{++}$, the common factor}

The fail-safe model contains a second implied prediction that special situations would arise where such critically low cell $\left[\mathrm{Mg}^{++}\right]$levels would occur. Indeed, in at least one situation, a large rapid severe decline in intracellular free $\left[\mathrm{Mg}^{++}\right]$ is known to occur (down to $\sim 0.25 \mathrm{mmol} / \mathrm{L}$ ) - about half the normal minimal level for a normal cell - which usually runs in the physiological range of $0.5-1.0 \mathrm{mmol} / \mathrm{L}^{25,26}$ and is associated with tissue injury and with a lowered cell [ATP] after TBI. ${ }^{33-35}$

It is proposed that $\mathrm{Li}^{+}$augments latent homeostatic adaptations to increase cell resilience and the ability to adapt and survive in hazardous conditions accompanied by and associated with sub-optimal $\left[\mathrm{Mg}^{++}\right]$levels, which also appear to reflect altered cell [ATP] levels.

Inositol depletion and its less considered inositol phosphate enhancement counterpart emerge as separate, semiindependent sub-components that - as well as appearing to help to regulate mood - also mediate cell protection. It is proposed that these protective mechanisms help regulate and stabilize intracellular $\left[\mathrm{Mg}^{++}\right]$and $\left(\right.$as $\mathrm{Mg}^{++}$forms a complex with ATP) help to stabilize cell energy levels, potentially at times also buffering any excess cell $\mathrm{Mg}^{++} / \mathrm{Ca}^{++}$and similar metal ions.

The role of the IMPase needs to be re-interpreted as representing a subtle fail-safe mechanism, compared to the more easily visible protective actions secondary to the inhibition of GSK-3. The new model also addresses lithium's action on other $\mathrm{Mg}^{++}$-requiring and $\mathrm{Li}^{+}$-sensitive systems G-proteins, adenylate cyclase, beta-arrestin, ${ }^{8,12,16,36}$ etc. - and related aspects, including metal ion toxicity and various forms of excito-toxicity.

The implications for the modes of action of valproate and carbamazepine are discussed in outline.

\section{Basic magnesium facts}

The level of cytosolic and mitochondrial $\mathrm{Mg}^{++}$is partly maintained by binding to numerous low-affinity sites. ${ }^{37-39}$ 
$\mathrm{Mg}^{++}$also binds to ATP and inorganic phosphates, Pi, and also binds strongly to inorganic pyrophosphate (PPi). ${ }^{37}$

The cell ratio of $\mathrm{Mg}^{++}$to $\mathrm{Ca}^{++}$seems to be about 2,000:1. Transport and sequestration within organelles appear to contribute to $\mathrm{Mg}^{++}$regulation; stable cell function seems to require a fairly stable cytosolic free $\left[\mathrm{Mg}^{++}\right]$concentration. ${ }^{40}$ The minutiae of cell $\mathrm{Mg}^{++}$homeostasis remain somewhat mysterious, ${ }^{40}$ and changes in the "buffering system" seem to have an important role ${ }^{38}$ consistent with preserving a homeostatic background. ${ }^{40}$ Intracellular $\mathrm{Mg}^{++}$appears to have a permissive role, ${ }^{40}$ supporting mechanisms mediated by $\mathrm{Ca}^{++} . \mathrm{Mg}^{++}$acts as a more long-term regulatory factor that "controls the set point or gain of a system". ${ }^{39,41}$ Romani and Scarpa ${ }^{25}$ and Romani ${ }^{26}$ gave the usual physiological range of free $\left[\mathrm{Mg}^{++}\right]$concentration between 0.5 and $1 \mathrm{mmol} / \mathrm{L}$.

\section{How the system works: different levels and different modes of fail- safe responses}

\section{Lithium non-responsive enzymes (Group 0)}

It is logical that there should be adaptive responses to a lowered cell $\mathrm{Mg}^{++}$; as $\left[\mathrm{Mg}^{++}\right]$levels drop, there will be regulatory changes across the range of $\mathrm{Mg}^{++}$-requiring systems to maintain homeostasis. $\mathrm{Li}^{+}$acts as a competitor ion for $\mathrm{Mg}^{++}$cofactor-requiring enzymes, but $\mathrm{Li}^{+}$intrudes only minimally into this process in the case of "ordinary" enzymes as $\mathrm{Li}^{+}$only seems to displace $\mathrm{Mg}^{++}$from a few specific, key enzymes, particularly those appearing to be related to mood disorders. ${ }^{42}$

The non- $\mathrm{Li}^{+}$-sensitive, ordinary $\mathrm{Mg}^{++}$-requiring enzymes achieve this selectivity by maintaining a high localized $\left[\mathrm{Mg}^{++}\right] /$ $\left[\mathrm{Li}^{+}\right]$concentration ratio. ${ }^{42}$ Ordinary $\mathrm{Mg}^{++}$-requiring enzymes thus remain largely insensitive to lithium, and will not be hindered by $\mathrm{Li}^{+}$, but will tend to adapt to changes in cell free $\left[\mathrm{Mg}^{++}\right]$. Common enzymes will not have their activity much altered by $\mathrm{Li}^{+}$, limiting its potential to produce unwanted effects.

\section{Basic protection: adaptation where $\mathrm{Li}^{+}$ competes directly with $\mathrm{Mg}^{++}$(Group I)}

The $\mathrm{Li}^{+}$effects on the GSK-3 variants, adenylate cyclases, G-proteins, and related beta-arrestin ${ }^{8,36}$ systems all operate by the same $\mathrm{Li}^{+}$competition with $\mathrm{Mg}^{++}$mechanism, ${ }^{8}$ and as in the case of GSK- $3,{ }^{6}$ other $\mathrm{Mg}^{++}$chelators, such as inositol phosphate, at relatively higher concentrations of ATP would be expected to further limit these enzymes. ${ }^{6}$

Enzyme activity within this group will adapt to changes in the availability of $\mathrm{Mg}^{++}$; this would cross-interact and change in the presence of lithium - ie, to react - as if the local cell $\left[\mathrm{Mg}^{++}\right]$concentration had been reduced.

$\mathrm{Mg}^{++}$loading of intact renal cells abolishes the inhibitory effects of $\mathrm{Li}^{+} .{ }^{43,44}$ Lithium directly inhibits the activation of vasopressin-sensitive adenylate cyclase in renal epithelia (again by competing with $\mathrm{Mg}^{++}$) for the activation of G-proteins. This direct effect on the activation of G-proteins accounts for the inhibitory effect of lithium on cAMP production in the intact cell. ${ }^{42}$ Lithium's effects on G-proteins are dependent on the $\left[\mathrm{Mg}^{++}\right]$concentration, again with the evidence of $\mathrm{Li}^{+} / \mathrm{Mg}^{++}$competition for binding. ${ }^{45}$

$\mathrm{Mg}^{++}$, as well as regulating the catalytic unit of adenylate cyclase, also regulates both activating and inhibitory sets of G-proteins. ${ }^{46,47}$ Lithium appears to counteract the regulatory effect of $\mathrm{Mg}^{++}$on the catalytic protein; $\mathrm{Mg}^{++}$ reverses $\mathrm{Li}^{+}$inhibition of adrenergic and muscarinic-induced GTP binding. ${ }^{47}$

At the G-proteins, adenylate cyclase, Akt/beta-arrestin- $2^{8,36}$ interactions, and GSK-3 level, ${ }^{6}$ there appears to be more direct competition between $\mathrm{Mg}^{++}$and $\mathrm{Li}^{+}$. The activity of these systems appears directly modulated by cytosolic $\left[\mathrm{Mg}^{++}\right]$ availability, but if lithium is also present, these particular enzymes will appear driven to (over)compensate as if the effective intracellular $\left[\mathrm{Mg}^{++}\right]$concentration were lower than it actually is, ie, the presence of $\mathrm{Li}^{+}$would "exaggerate" the magnitude of the corrective response.

Within this group of enzymes, the added presence of $\mathrm{Li}^{+}$ begins to "augment" the adaptive response to a lowered cell $\left[\mathrm{Mg}^{++}\right]$concentration; the cell tends to behave as if its internal $\left[\mathrm{Mg}^{++}\right]$concentration had been reduced to compensate accordingly, providing a basic adaptive mechanism supporting more "exotic" fail-safe mechanisms.

\section{The IMPase and IPPase: more exotic fail- safe mechanisms (Group 2)}

The members of this key group of magnesium-dependent and lithium-sensitive phosphatases (particularly, the IMPase and IPPase) have the kinetics and specific properties that indicate that they have the ability to form subtle components of a low cell $\left[\mathrm{Mg}^{++}\right]$fail-safe system; in effect, they also form part of a "low cell $\left[\mathrm{Mg}^{++}\right]$management" and "sensing" system capable of activating more specialized forms of the "failsafe system" and appear to utilize various sub-mechanisms, including "InsPhosphate enhancement", and other related sub-mechanisms, eg, metal or ATP chelation (see 'Inositol phosphates and related sugar phosphates as potential complimentary/supplementary $\mathrm{Mg}^{++} / \mathrm{Ca}^{++}$buffers' section). Why cells with a low $\left[\mathrm{Mg}^{++}\right]$require this enhanced protection 
may require more explanation; to the imperative to optimize protection in the crisis conditions following TBI; conditions critically co-existing with a very low cell $\left[\mathrm{Mg}^{++}\right],{ }^{32,33}$ so that the low cell $\left[\mathrm{Mg}^{++}\right]$also at times, appears to be recruited as an alarm signal to mobilize the maximal available (brain) cell protection (see 'The magnesium abyss' section).

The apparent linkage of this system to the response to TBI might appear to catastrophically fail to account for certain actions of $\mathrm{Li}^{+}$, eg, lithium's acute inhibition of glutamate reuptake ${ }^{48}$ appears paradoxical, as it would tend to worsen the effects of excess glutamate-related excito-toxic activity, but remains relevant in a post TBI situation, as in the early phases of the post TBI situation, the normal direction of flow of membrane pumps - due to a severe lack of cell energy and membrane depolarization - actually appears to be reversed.

Within this group of enzymes (or at least the IMPase and IPPase), lithium acts by augmenting the activation of specialized, (low cell $\left[\mathrm{Mg}^{++}\right]$related) more specific fail-safe systems; again with $\mathrm{Li}^{+}$present, the enzymes then react as if the local cell $\left[\mathrm{Mg}^{++}\right]$concentration had been reduced and will tend to compensate for the effects of the apparently lowered $\left[\mathrm{Mg}^{++}\right]$by activating corrective mechanisms. With recovery, with $\mathrm{Li}^{+}$present, the cell $\left[\mathrm{Mg}^{++}\right]$concentration would tend to be (over)corrected and stability regained, and the protection mechanisms no longer required switch off and disappears into the background as the cell $\left[\mathrm{Mg}^{++}\right]$returns to normal or, with $\mathrm{Li}^{+}$present, perhaps to even slightly above prior, normal levels.

The combined activation of these different protective responses - spread across the various systems (cAMP, G-proteins, GSK-3, etc.) and mediated by the combined effects of the various proposed low $\left[\mathrm{Mg}^{++}\right]$-sensitive, more specialized protective sub-mechanisms - would generate lithium's total therapeutic effect and would tend to lead to the normalization of mood, including the eventual restoration of cell $[\mathrm{ATP}]$ and the bolstering of cell $\left[\mathrm{Mg}^{++}\right]$concentrations, resolving the "episode".

The model implies that the therapeutic action of lithium is distributed across the proposed mechanisms. There is no "single point of action" for lithium, an " $\mathrm{Mg}^{++}$ion-antagonist analog" or a "low cell $\left[\mathrm{Mg}^{++}\right]$" mimic.

While $\mathrm{Li}^{+}$, at root, mimics the action of a lower cell $\left[\mathrm{Mg}^{++}\right]$ level, $\mathrm{Li}^{+}$is likely to have some residual, non-specific actions that may also limit the tolerable dose.

Not all of lithium's actions need to be, or are perhaps likely to be, mediated via the proposed mechanisms. $\mathrm{Li}^{+}$is not a perfect "low cell $\left[\mathrm{Mg}^{++}\right]$mimetic"; $\mathrm{Li}^{+}$resembles $\mathrm{Na}$, $\mathrm{K}+$, and $\mathrm{Ca}^{++}$ions, a little also. ${ }^{19}$

Other than the direct and indirect multi-leveled cascade effects of opposing displacing $\mathrm{Mg}^{++}, \mathrm{Li}^{+}$ions appear devoid of possessing significant catalytic or "active" effects.

Inositol depletion, inositol phosphate enhancement and $\mathrm{Mg}^{++} / \mathrm{Ca}^{++}$chelation; semi-independent, latent fail-safe mechanisms

Agranoff and Fisher ${ }^{49}$ suggested that neuronal signal transduction might be suppressed as a consequence of $\mathrm{Li}^{+}$-induced inositol phosphate accumulation.

$\mathrm{Li}^{+}$in blocking the IMPase, in "depleting" myo-inositol, $\mathrm{Li}^{+}$also has the effect of "accreting" or "enhancing" the levels of myo-inositol monophosphates; ${ }^{49}$ Ins $1 \mathrm{P}$, actually a collection of myo-inositol(4)P, Ins(1)P, plus Ins(3)P, and via also by inhibiting the IPPase; myo-inositol bisphosphate, Ins- $(1,4)$ bisphosphate, InsP $2,{ }^{49}$ as well as CMP-PA, ${ }^{50}$ and potentially other "minor" sugar phosphates including galactose-1P (see the 'Lithium's inhibition of PGM' section).

The implications of the rise in the levels of myoinositol phosphates - InsP1/InsP2 or various other sugar phosphates - seems to have been less explored as InsP is not a (conventional) "signaling molecule"., 1,2 The consequent lithium-induced inositol phosphate enhancement or "sugar phosphate enhancement" is as real, and of the same general magnitude, as the simultaneously induced "inositol depletion", and a rise in InsP1 and InsP2 will simultaneously also trap - "deplete" - the corresponding finite amount of cell Pi (inorganic phosphate). The inhibition of the IMPase manifests as inositol depletion has the effect of creating inositol phosphate enhancement, which crucially generates additional cell $\mathrm{Mg}^{++}$- and $\mathrm{Ca}^{++}$-buffering capacity, as carbohydrate and cyclitol phosphates (sugar phosphates) are $\mathrm{Ca}^{++}$and $\mathrm{Mg}^{++}$ metal-ion chelators (Figure 1)..$^{51,52}$

\section{Key evidence: the matching $\mathrm{Mg}^{++}$and $\mathrm{Li}^{+}$kinetics of the IMPase, IPPase, and GSK-3}

$\mathrm{Li}^{+}$acts via an uncompetitive mechanism. $\mathrm{Li}^{+}$displaces an $\mathrm{Mg}^{++}$from the IMPase active site. ${ }^{2,4}$ The higher the concentration of substrate, the greater the degree of inhibition. ${ }^{1,2}$

Lithium acts as a competitive inhibitor of numerous $\mathrm{Mg}^{++}$-dependent factors, transporters, and enzymes. ${ }^{4} \mathrm{Li}^{+}$is an uncompetitive inhibitor of the IMPase $\mathrm{Mg}^{++}$binding and is an uncompetitive inhibitor of myo-inositol-1-phosphate binding. ${ }^{1,2,4,7}$

Direct support of $\mathrm{Mg}^{++}$being fundamentally involved in the mode of action of lithium is provided by the kinetics 


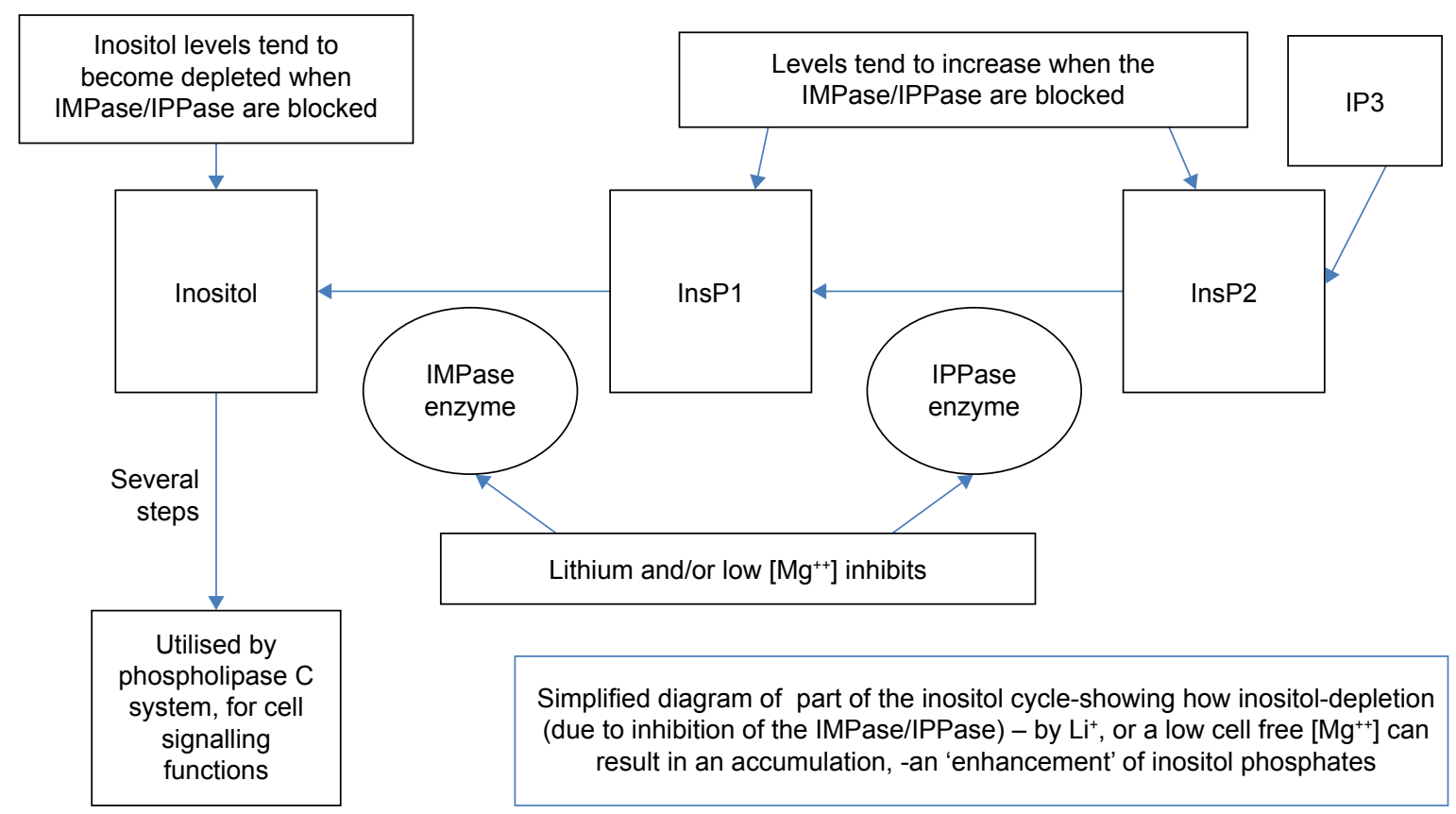

Figure I Inositol cycle showing how blockage of IMPase creates inositol depletion and inositol phosphate enhancement.

Notes: Blockage of the IMPase and IPPase reduces recycling and availability of inositol required to form PIP2, needed to generate DAG and IP3 second messengers. See references Berridge et al, ${ }^{2}$ Harwood, ${ }^{11,54}$ and Agranoff and Fisher ${ }^{49}$ for further details of the inositol signaling pathway.

Abbreviations: IMPase, inositol monophosphatase; IPPase, inositol polyphosphate-I-Phosphase.

of the IMPase itself; remarkably, Gore et $\mathrm{al}^{53}$ showed that the effects of $0.8 \mathrm{mmol} / \mathrm{L} \mathrm{Li}^{+}$are potentially more or less equimolar in effect on the IMPase, to the limiting inhibitory effect of a lower to mid-range cell $\left[\mathrm{Mg}^{++}\right]$.

Thus, a lowered cell free $\left[\mathrm{Mg}^{++}\right]$potentially does much the same thing to the IMPase as $\mathrm{Li}^{+}$; a moderate-to-low cell $\left[\mathrm{Mg}^{++}\right]$concentration appears to have a potential inbuilt lithium-like action at least if system turnover (receptor activation) is sufficient.

Approximately $0.6-0.7 \mathrm{mmol} / \mathrm{L} \mathrm{Mg}^{++}$(about the mean mid-range of the full cell $\left[\mathrm{Mg}^{++}\right]$concentration range $0.25-1.1 \mathrm{mM}$ ) permits only half-maximal activity in the native IMPase enzyme (activity peaks at $1 \mathrm{mmol} / \mathrm{L}$ and then flat to $\sim 5 \mathrm{mmol} / \mathrm{L}$ ) and drops steeply, ie, "grinds almost to a halt" to a low plateau of $10 \%-15 \%$ (maximum) activity; below $0.35 \mathrm{mM} / \mathrm{L} \mathrm{Mg}^{++}$, the IMPase activity drops precipitously - remarkably steeply - with the loss of roughly $50 \%$ enzyme activity, between 0.65 and $0.35 \mathrm{mmol} / \mathrm{L}$ of intracellular $\left[\mathrm{Mg}^{++}\right.$(refer Figure 5 of Gore et al; ${ }^{53}$ an average dose of lithium $0.6 \pm 0.14 \mathrm{mmol} / \mathrm{L}=50 \%$ inhibition $=$ cell $\left[\mathrm{Mg}^{++}\right]$ level of, say, $0.6-0.7 \mathrm{mmol} / \mathrm{L}$ ).

The kinetics reflect the full dynamic range $-0.25-1.1$ $\mathrm{mmol} / \mathrm{L}$ - of the expected potential range of intracellular $\left[\mathrm{Mg}^{++}\right]$concentrations. This inflection point, with a sharp transition at around the lower-mid-range of the full normal cell $\left[\mathrm{Mg}^{++}\right]$concentration range, suggests that this may be part of a true regulatory system, with a system activation threshold below $\sim 0.6-0.7 \mathrm{mmol} / \mathrm{L}$, suggesting that in some cells, the system (including some background GSK-3 inhibition) may be partly operational during normal activity. A $0.8 \mathrm{mmol} / \mathrm{L}$ lithium is supposed to produce $\sim 50 \%$ IMPase inhibition; ${ }^{4}$ this approximates to a cell $\left[\mathrm{Mg}^{++}\right]$level of $\sim 0.6-0.7 \mathrm{mmol} / \mathrm{L}$ about the lower-mid-point of the normal range of cell $\left[\mathrm{Mg}^{++}\right]$ concentration $(0.25-1.0 \mathrm{mmol} / \mathrm{L})$ and with a normal resting, "dwell" point of roughly $0.6 \mathrm{mmol} / \mathrm{L} .^{25,26}$

Lithium has effects clinically observable at quite low concentrations, suggesting that there is not always any great surplus of brain IMPase activity, which appears to be thus effectively "rate-limiting"; this suggests that the prevailing intracellular $\left[\mathrm{Mg}^{++}\right]$concentration does have a relevant physiological and a real regulatory effect. Conversely, conditions of a drop of cell free $\left[\mathrm{Mg}^{++}\right]$to $\sim 0.5 \mathrm{mmol} / \mathrm{L}$ to the edge of the "low cell $\left[\mathrm{Mg}^{++}\right]$Abyss" provides potentially about as much "in-built-lithium-like action" as a standard $0.7-0.8 \mathrm{mmol} / \mathrm{L}$ dose equivalent of lithium.

It appears a challenge for the standard inositol depletion model that a mid-range of cell free $\left[\mathrm{Mg}^{++}\right]$concentration appears to have the same degree of potential inhibitory (ratelimiting) activity on the IMPase as standard lithium therapy and will have the potential to produce the same potential degree of notional inositol depletion/"InsP enhancement" as a therapeutic concentration of lithium, ie, be moreor-less "equivalent" to $\mathrm{Li}^{+}$at least if the two different modes of inhibition - "uncompetitive" ${ }^{50}$ versus a lack of an 
essential $\mathrm{Mg}^{++}$metal cofactor - does not skew this argument too greatly.

One obvious way that the system (say in "bipolar disorder") might become desensitized - and hence require boosting by $\mathrm{Li}^{+}-$is an increase in IMPase numbers. ${ }^{54}$ The Gore et $\mathrm{al}^{53}$ kinetics shows the potential for a rather greater degree of inhibition of the IMPase by a low cell $\left[\mathrm{Mg}^{++}\right]$(below an intracellular concentration of $\sim 0.35 \mathrm{mM} \mathrm{Mg}^{++}$) - down to $\sim 10 \%-15 \%$ of capacity - than by typical doses of lithium -

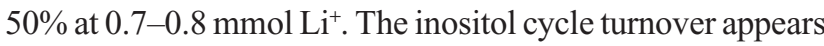
to be set "too high" in the bipolar ("manic") disease state, ${ }^{1,2}$ it is this faster turnover that would permit a lack of the $\mathrm{Mg}^{++}$ ion cofactor to limit IMPase enzyme activity.

Given the common core structure ${ }^{21}$ the lithium, and the $\mathrm{Mg}^{++}$sensitivities of these other $\mathrm{Mg}^{++}$-dependent enzymes, these related enzymes might be thought likely to have similar $\mathrm{Mg}^{++}$requirements. The $\mathrm{Li}^{+}$-sensitive IPPase (which also can break down Ins-1,3,4) requires somewhat less $\left[\mathrm{Mg}^{++}\right]$; the IPPase requires only $\sim 0.3 \mathrm{mmol} / \mathrm{L} \mathrm{Mg}^{++}$for $50 \%$ activity, ${ }^{55}$ and its sigmoidal response also appears somewhat more linear than that for the IMPase $-53,55$ - it appears that the IMPase is the primary site of the system's regulation (except perhaps if the IMPase is mutated, or IMPase numbers are much increased, or cell $\left[\mathrm{Mg}^{++}\right]$levels very low).

The ratio of InsP1 versus InsP2 accumulation may give some indication of prevailing cell $\left[\mathrm{Mg}^{++}\right] /\left[\mathrm{Li}^{+}\right]$levels, as InsP2 would tend to increase proportionately rather more in the lower ranges of $\left[\mathrm{Mg}^{++}\right]$levels. This would imply - in the post TBI situation (see 'The magnesium abyss' section) - an at least $50 \%$ inhibition of the IPPase; note also that if the IMPase were a mutant - a non- $\mathrm{Li}^{+}$-sensitive form - it would then require a further mutation of the IPPase to lose all protection (at least via the inositol depletion/InsP enhancement mechanism), ie, it implies that even "non-lithiumsensitive" subjects would still preserve a residual degree of protection, eg, against TBI, but the protection would be inferior. This predicts that poor or non- $\mathrm{Li}^{+}$responders akin to "schizophrenics" would tend to do worse post head injury-type brain insults.

A low cell $\left[\mathrm{Mg}^{++}\right]$level does appear to cause a true membrane PI, (phosphatidyl inositol) depletion ${ }^{56}$ in cardiac muscle cells. The characteristics of the IMPase, IPPase, and GSK-3 enzymes match the proposed model perfectly; the proposed system could not work if the kinetics were very much different - much more stringent than just matching a single point on the complex and unusual concentration curve.

It follows that lithium would do little, and could do little that was useful, in normal systems, ie, in cells with normal $\left[\mathrm{Mg}^{++}\right]$levels, normal [ATP] levels, and normal IMPase numbers and with a normal ("non-manic") turnover rate. Lithium "turbo-charges" the effects of a low cell $\left[\mathrm{Mg}^{++}\right]$, particularly if IMPase numbers are increased, by providing additional inhibition of the IMPase, IPPase, BPNase, FBPase, adenylate cyclase, and GSK-3, etc., and perhaps additional auxiliary $\mathrm{Mg}^{++} / \mathrm{Li}^{+}$-sensitive systems.

Thus, lithium can partly compensate for a modest increase (it would appear, by extrapolation, a 2-3-4-fold) in IMPase numbers, the extra inhibition that lithium donates potentially compensating for the increased enzyme activity due to an expansion of IMPase numbers, restoring the system equilibrium to a similar state that existed before the IMPase numbers increased. A 50\% inhibition of the IMPase (cell $\left[\mathrm{Li}^{+}\right]$of $\sim 0.8 \mathrm{mmol} / \mathrm{L}$ ), leaving aside additional effects mediated via GSK-3, etc., would be roughly equivalent to a halving of the IMPase numbers, indicating that the range of lithium's compensation - such as the therapeutic dose range - is limited.

It may be questioned, if a low cell $\left[\mathrm{Mg}^{++}\right]$has latent potential in-built $\mathrm{Li}^{+}$-like activity, why then should lithium ever be required? It seems to be only in those with sufficient vulnerability to mood disorders that this becomes critical, as the system of an intrinsic, lithium-like mood-stabilizing action may be working perfectly well in those - the bulk of the population - who remain "resilient".

The proposed mechanism offers an elegant, selective, "automatic" mood-stabilizing, and cell-resilience mechanism regardless of the minutiae of the mode of action. The in-built potential $\mathrm{Li}^{+}$-like action of a mid-range $\mathrm{Mg}^{++}$concentration on the IMPase, suggested by the Gore et $\mathrm{al}^{53}$ kinetics, provides an in-built survival advantage to the organism, a high degree of innate resilience mood stabilization and multifaceted cell protection. The buffering system may carry some biological costs, which may create a potential for mood swings. The cell death/atrophy that appears at risk of occurring in mood disorders has been conceptualized as arising from an impairment of "cell resiliency". 57

If the IMPase numbers were to increase a few times, an excess of myo-inositol would then leak past the blockade and the proposed "buffering/depletion system" would start to break down. Harwood ${ }^{54}$ proposed that changes in IMPase numbers are a key variable - an important interface between genetic and environmental factors determining vulnerability to mood disorders.

The way the system seems to work suggests that an increase in IMPase numbers would be fundamental to the in-built regulation - the innate mood stabilizing, cell protection, and "resiliency" - the protection provided by the IMPase, IPPase, and enzyme kinetics, and the regulation of 
cell $\left[\mathrm{Mg}^{++}\right]$sometimes breaking down; this may be why some individuals need lithium as a "top-up".

The IPPase might become a more important ("reserve") secondary site of regulation if IMPase numbers become substantially increased or "in severe crisis" if cell $\left[\mathrm{Mg}^{++}\right]$ levels drop very low. Inhibiting any excess IMPase enzyme activity with added $\mathrm{Li}^{+}$would tend to restore InsP chelation buffering and encourage the retention/recapture of some of the cell $\mathrm{Mg}^{++}$to help limit potential damage caused by low cell $\left[\mathrm{Mg}^{++}\right]$levels.

Lithium would have a greater effect in a low $\left[\mathrm{Mg}^{++}\right]$(and lower [Mg-ATP] a lower cell energy) environment - less competition with $\mathrm{Mg}^{++}$and (general and "specific") enzyme activities (including GSK-3), already reduced, limited by a relative lack of cell $\left[\mathrm{Mg}^{++}\right]$.

It is postulated that the main effects of lithium on mood are mediated by mimicking the effect of a lower cell $\left[\mathrm{Mg}^{++}\right]$, thus sending an amplified cellular "distress signal"; this helps compensate for any modest increase in IMPase numbers, providing overall increased cell protection, including increased $\mathrm{Mg}^{++}$and $\mathrm{Ca}^{++}$buffering and stabilization, in the longer term, the restoration and bolstering of brain cell $\left[\mathrm{Mg}^{++}\right]$, and correction of IMPase numbers, helping restoring cell energetics by optimizing ATP levels and the ATP- $\mathrm{Mg}^{++} / \mathrm{Pi}$ ratio. Phosphate compounds can form chelates with $\mathrm{Mg}^{++}$, and excess $\mathrm{Mg}^{++}$ions - in proportion to phosphate or ATP - may reduce cellular energetic efficiency ${ }^{58}$ this might be relevant to weight gain on lithium. A multi-way InsP/sugar-Phosphate-/ Galactose-P/Mg-ATP (potentially also a polyamine-ATP chelation) interaction to modulate energetic efficiency acting on the very core of the $\left[\mathrm{Mg}^{++}-\mathrm{ATP}\right]$ related interactions.

\section{Inositol phosphates and related sugar phosphates as potential complementary/supplementary $\mathrm{Mg}^{++} / \mathrm{Ca}^{++}$ buffers}

Phytic acid, InsP6, is a well-known calcium-binding agent. Lutrell ${ }^{51,52}$ demonstrated that carbohydrate phosphates, cyclitol phosphates, nucleotides, and nucleic acids are weak $\mathrm{Ca}^{++}$and $\mathrm{Mg}^{++}$chelators; weak $\mathrm{Mg}^{++}$"buffers" become more potent with more functional binding groups. Lutrell ${ }^{51,52}$ suggested that $\mathrm{Mg}^{++}$chelate formation was intrinsic to the action of both IMPase and IPPase enzymes and that $\mathrm{Mg}^{++} / \mathrm{Ca}^{++}$ "chelation coupling" provided a mechanism for the control of events; Lutrell did not discuss this in connection with the $\mathrm{Mg}^{++}$requirements of the IMPase, effects on mood, or link this to the inositol depletion concept.

An accumulation of various sugar/inositol phosphates - as a result of lithium (and/or the effects of a low intracellular
$\left[\mathrm{Mg}^{++}\right]$level) - potentially represents an additional pool of $\mathrm{Mg}^{++}$binding (and $\mathrm{Ca}^{++}$binding) "buffering" capacity (with differing binding coefficients/affinities) - yet potentially capable of retaining more cell $\mathrm{Mg} / \mathrm{Mg}^{++}$, than in cells lacking such a $\mathrm{Mg}^{++}$chelation/buffering system, and in the case of calcium, helping to act as a potential $\mathrm{Ca}^{++}$- "firewall"; to clamp, and limit the travel of excessive local $\mathrm{Ca}^{++}$"spikes".

A mixture of various sugar phosphates, including G-6-P and galactose-1-P, inositol phosphates (Ins1P, InsP2, Ins-1,4P), and the higher Ins-phosphates would provide a potentially flexible $\mathrm{Mg}^{++}$and $\mathrm{Ca}^{++}$buffering subsystem. Galactose phosphate is also a form of IMPase substrate and IMPase inhibitor and has been proposed as a potential regulator of the IMPase. ${ }^{59}$

Lutrell $^{51,52}$ noted that affinity increases with the number of phosphate substituents on the sugar ring and suggested that the stereochemistry would also be relevant. Lutrel151 suggested that for the relevant various inositol phosphates, half-maximal $\mathrm{Ca}^{++}$binding would occur in the concentration range of $\sim 5 \times 10^{-6}$ to $2 \times 10^{-4} \mathrm{M}^{51,52}$

Lithium also causes an increase in cytidine monophosphoryl phosphatidate (CMP-PA), which in conditions of reduced inositol availability also tends to accumulate ${ }^{50}$ another - albeit, a membrane-bound - $\mathrm{Mg}^{++}$-binding agent. This would appear to represent a complex buffering system, also involving, eg, creatine phosphate, F-1,6,-biphosphate, ATP/ADP, and citrate, most obviously relevant to higher cell energy states, probably binding $\mathrm{Mg}^{++}$at higher energy levels - at higher [ATP] and $\left[\mathrm{Mg}^{++}\right]$concentrations.

What is required is a system to meet the requirements of the cell under varying conditions. The inositol phosphate and sugar phosphate (including galactose-P) series may provide a potentially flexible (regulatory) sub-component of an $\mathrm{Mg}^{++}$ $\mathrm{Ca}^{++}$buffering fail-safe chelating system. This would extend the role of the inositol system to include $\mathrm{Mg}^{++} / \mathrm{Ca}^{++}$, metal-ion chelation (and detoxification), and ATP-related mechanisms.

In conditions of low cell $\left[\mathrm{Mg}^{++}\right]$, lithium is likely to have a greater effect in increasing InsP levels. The data of Gore et $\mathrm{al}^{53}$ suggest that the system is activated (IMPase limited) when $\mathrm{Mg}^{++}$levels sink to below $\sim 0.45-0.5 \mathrm{mmol} / \mathrm{L}$, providing the advantages of a potential built-in cell protection system, an intrinsic lithium-like, mood-stabilizing mechanism, regardless of the precise mode of action.

The lower pole of the cell $\left[\mathrm{Mg}^{++}\right]$concentration range would more obviously require additional buffering, as at the upper pole, $\mathrm{Mg}^{++}$can either (presumably) be released to the outside of the cell and/or (presumably) normally be buffered by ATP/ADP, citrate, etc., or absorbed by mitochondria, etc. 
There is the possibility that InsP might at times act merely as a $\mathrm{Ca}^{++}$buffering/binding ( $\mathrm{Ca}^{++}$"firewall”) system, as cell $\left[\mathrm{Ca}^{++}\right]$concentrations are much lower than $\left[\mathrm{Mg}^{++}\right]$.

An inability to properly buffer cell $\mathrm{Ca}^{++}$may cause toxic cell injury and compromise cell viability. ${ }^{57}$ The proposed system would also tend to chelate - protect against other potentially toxic cations, $\mathrm{Fe}, \mathrm{Mn}, \mathrm{Zn}, \mathrm{Cu}, \mathrm{Al}$, etc. ${ }^{60}$

The various other "minor sugar phosphates" (perhaps particularly galactose-P) could potentially also act as nearequivalent $\mathrm{Mg}^{++} / \mathrm{Ca}^{++}$buffers in place of InsP1/P2. Further, pentose phosphate pathway (PPP)-derived minor sugar phosphate products are likely to increase in the event of a rise in ROS, which stimulates the PPP activity. Is it possible that a rise in minor sugar phosphates could potentially be adjunctive (somewhat equivalent) to Ins-phosphate in neurons, in terms of $\mathrm{Mg}^{++} / \mathrm{Ca}^{++}$buffering, potential IMPase substrate inhibiting, and/or also providing indirect antioxidant action (via toxic metal-ion binding), ${ }^{60}$ even possible a further regulatory action (the activity of PI synthase in yeast, which competes with PS synthase, is elevated in zinc-deficient cells, so that InsP, if it chelates zinc, might help regulate [increase] PI synthase activity).

Chelating agents, binding copper or iron, appear to have (indirect) antioxidant effects ${ }^{60}$ and are also able to block hydrogen peroxide formation caused by amyloid (and by potentially binding (eg, $\mathrm{Cu} / \mathrm{Zn}$ ) metal ions that might help precipitate abnormal folding of unstable proteins), so that the proposed inducible "low $\left[\mathrm{Mg}^{++}\right]$, InsP chelating mechanism" may offer wider protective properties, potentially limiting damage from high $\mathrm{Ca}^{++}$, and its consequences, or other toxic metals, eg, in abnormal protein-folding conditions, such as Alzheimer's (which also suggest that conditions of low cell $\left[\mathrm{Mg}^{++}\right]$might be relevant to this) ${ }^{61}$ (see "Conformational disease, protein folding" section).

Lithium - if it sets up a reservoir of Ins-phosphates, in some cells, under certain circumstances (particularly with cell $\left[\mathrm{Mg}^{++}\right]$ depletion, alongside its actions via GSK-3) - might also shift cell protein phosphorylation patterns and, by depleting Pi (inorganic phosphate), also tend to limit ATP, high energy-phosphate formation (and might potentially help to tend to shunt part of a finite pool of Pi away from, eg, a Tau hyper-phosphorylation "accident"). Compounds that stabilize intracellular $\left[\mathrm{Ca}^{++}\right]$ protect against Alzheimer' ${ }^{61}$ inhibition of inositol 1,4,5-trisphosphate binding to its receptor by InsP chelation might limit InsP3-mediated increases in intracellular $\mathrm{Ca}^{++}{ }^{51,52}$

If turnover is slow, there might be a reduced potential for Ins-P/sugar phosphate accumulation; hence, there would be less scope to safely "shunt" any excess cell phosphate if there is any relative "surplus" of $\mathrm{Pi}$, which could increase potential risk of Tau hyper-phosphorylation.

As well as the various inositol phosphates and G-6-P, there is group of further "minor" Phosphor-sugars; these are interesting, as potential "analogues" of InsP1; as additional further substrates ${ }^{62}$ of the IMPase - including G-3-P, (the PPP related); erythrose 4-P, ribose 5-P, G6-P, FBP, F6-P, xylose 5-P, galactose-1/6-P, and similar compounds.

The IMPase has evolutionary links to glycolysis; the IMPase is a highly conserved enzyme, with localized structural similarity to glycerol 3-phosphate dehydrogenase. ${ }^{62}$ There are also structural similarities between FBPase and the IMPase. ${ }^{63}$ The type 1 "IMPase" appears to be a curiously non-specific phospho-sugar phosphatase - an important clue to the deeper meaning of the original proposal.

The chemical similarity of these small sugar phosphate molecules, which also make up part of the PME peak, ${ }^{50}$ suggests that they might complement the substrate-like, "grid-lock"-like action of InsP and could perhaps have relevant similar or additional/complementary inhibitory effects on the uncompetitively acting IMPase(s)/(and possibly act on further $\left[\mathrm{Mg}^{++}\right]$-related downstream systems, eg, the CDP-PI synthase)? Note the possibility that such "substrate inhibition" might potentially still apply to some other, non-type 1 IMPase, non-lithium-sensitive, mutant IMPase variants. Potentially, the buffering from the "minor sugar phosphates", related to the PPP (perhaps particularly galactose-P) would appear to represent additional, constitutive components of the system that would not require receptor drive, or "fast" turnover, to set up or maintain.

There is the possibility that similar "minor sugar phosphates" also accumulate, as further (Ins-P like) "pseudo"substrates for the IMPase/IPPase; if their concentrations become sufficient, these could also exert additional, Ins-Plike substrate inhibition on the IMPase, potentially further modulating turnover, or inhibiting, or possibly directly acting on or inhibiting various steps in the Ins-phosphate cycle, perhaps including ion channels. ${ }^{49,64}$

\section{More on the $\mathrm{Li}^{+} / \mathrm{Mg}^{++}$kinetics of the IMPase, IPPase, and GSK-3}

Lower cell concentrations of $\left[\mathrm{Mg}^{++}\right]$, eg, 0.6-0.7 mM/L potentially limits the IMPase as much as roughly the same level of lithium; ${ }^{53}$ this fundamental, curious fact appears to have been overlooked. Thus, a low cell free $\left[\mathrm{Mg}^{++}\right]$potentially does much the same thing to the IMPase as lithium; a mid-to-low range intracellular $\left[\mathrm{Mg}^{++}\right]$appears to have a potential in-built lithium-like, mood-stabilizing action. 
The system, if the IMPase is the "normal" $\mathrm{Li}^{+}$-sensitive wild type, will be restricted at a mid-concentration range of $\mathrm{Mg}^{++}$as intracellular $\left[\mathrm{Mg}^{++}\right]$levels can vary between 0.25 , $0.5,1.1 \mathrm{mmol} / \mathrm{L}^{25,26}$

Lithium will thus also tend to have a greater action in cells with a low $\left[\mathrm{Mg}^{++}\right]$, as the effects of the inhibition by low cell $\left[\mathrm{Mg}^{++}\right]$and the combined effects of inhibition by lithium on the IMPase, IPPase, adenylate cyclase, and GSK-3, etc., would be additive. This is parallel to the situation with GSK-3; lithium's inhibition of GSK-3 is again through competition with $\mathrm{Mg}^{++}$; the potency of $\mathrm{Li}^{+}$inhibition of GSK-3 is also dependent on the $\left[\mathrm{Mg}^{++}\right]$concentration. ${ }^{6}$

GSK-3 is also sensitive to the chelation of free $\mathrm{Mg}^{++}$by ATP $;{ }^{7}$ GSK-3 is thus also sensitive to further inhibition by other $\mathrm{Mg}^{++}$chelators, eg, by InsP or similar sugar phosphatelike compounds, GSK-3 is also progressively further inhibited when cell [ATP] concentrations are higher than that of $\left[\mathrm{Mg}^{++}\right]$, and also potentially, in the presence of other Ins-Plike sugar phosphate chelating-type compounds.

Given the cellular concentrations of ATP and $\mathrm{Mg}^{++}$ (as with the situation with the IMPase), lithium will have a greater effect on GSK-3 activity in vivo than expected from in vitro studies. GSK-3 enzymes require a high $\left[\mathrm{Mg}^{++}\right]$ in vitro concentration for maximal activity. ${ }^{6}$ The in vivo cell $\left[\mathrm{Mg}^{++}\right]$concentration is lower than that commonly used in many in vitro experiments, and at physiological $\left[\mathrm{Mg}^{++}\right]$ concentrations, $\mathrm{Li}^{+}$gives half-maximal inhibition of GSK-3 at $\sim 0.8 \mathrm{mmol} / \mathrm{L}^{7}-$ a match to the therapeutic concentration range - and again a perfect fit to the data for $\mathrm{Li}^{+}$on the IMPase $^{4,53}$ and IPPase. ${ }^{55}$

\section{Lithium's (uncompetitive) mode of action on the IMPase}

$\mathrm{Li}^{+}$acts via an uncompetitive enzyme mechanism; $\mathrm{Li}^{+}$displaces $\mathrm{a} \mathrm{Mg}^{++}$from the active site. ${ }^{2,4}$ The higher the concentration of substrate, the greater the degree of inhibition. ${ }^{1,2,4}$ Gee et al ${ }^{65}$ also suggested that this uncompetitive method of blocking the IMPase is possibly as important as its target - as it enables a large increase in InsP1 (and similar substrate) levels, particularly in putatively "overactive"//"overstimulated" cells. This may explain an unusual feature of the IMPase enzyme, which has been likened by Berridge et $\mathrm{al}^{3}$ to an inertia "seat-belt"-like mechanism. It may also explain the paradox that chronic lithium seems not always to greatly affect cell inositol or Ins-P. ${ }^{66}$ Lithium would have, and would need to have, little effect in cells with normal $\left[\mathrm{Mg}^{++}\right]$and "normal" levels of (receptor) turnover.

Consistent with the proposed role of this system in TBI, the mode of action of IMPase seems more akin to a "damage limitation" system rather than adapted to steady-state inhibition. Several studies suggest that inositol depletion is not always a long-term phenomenon. ${ }^{66} \mathrm{Mg}^{++}$seems to compete with $\mathrm{Li}^{+}$at the IMPase (low affinity site). ${ }^{2,4} \mathrm{~A}$ low intracellular $\left[\mathrm{Mg}^{++}\right]$will exert much the same effect as $\mathrm{Li}^{+}$; no amount of extra substrate(s) is likely to get through, regardless of substrate concentrations, if the enzyme activity is fundamentally restrained by a low $\left[\mathrm{Mg}^{++}\right]$availability.

\section{$\mathrm{Mg}^{++}$, mood and metabolic disorders}

The proposed new mechanism explains the anomalies and paradoxes of the inositol depletion model; suicide victims and brains of bipolar patients tend to have low frontal cortex myoinositol levels $;{ }^{67}$ this appears paradoxical as inositol depletion would be expected to protect - to a certain extent - against low mood, yet is consistent with a lower intracellular $\left[\mathrm{Mg}^{++}\right]$ level itself having a lithium-like, inositol-depleting effect; it suggests that the conditions associated with low brain cell $\left[\mathrm{Mg}^{++}\right]$are associated with a high suicide risk.

Eby and Eby ${ }^{68,69}$ reviewed evidence relating to magnesium in depression and cited a correlation between low $\mathrm{Mg}$ in soils to resilience and suicide rates - first noted by Robinet $^{70}$ - quoted in Eby and Eby. Patients who had made suicide attempts showed a significantly lower cerebrospinal fluid (CSF) magnesium, correlated with CSF 5-HIAA. ${ }^{71}$

Lithium reduces the suicide rate more efficiently than other treatments; ${ }^{72} \mathrm{Li}^{+}$also normalizes the death rate from cardiac and other medical causes, ${ }^{73}$ reflecting its broader protective actions. An inability to buffer cell $\mathrm{Ca}^{++}$may cause cell injury and compromise long-term cell viability. ${ }^{57}$

Magnesium, predictably, has mood-stabilizing properties. ${ }^{74}$ Heiden et $\mathrm{al}^{75}$ demonstrated improvement in resistant manic patients, treated with adjunctive magnesium. Grimaldi ${ }^{76}$ noted the potential for a cell $\left[\mathrm{Mg}^{++}\right]$deficiency to generate inositol depletion and reviewed the effects of magnesium deficiency in relation to Tourette's - albeit with a considerable comorbidity - including migraine, depression, with links to NMDA and kynurine systems, etc.

Wells ${ }^{77,78}$ considered that decreased intracellular $\mathrm{Mg}^{++}$and Mg-ATP constitute a key risk factor for type 2 diabetes and that beyond dietary factors, intracellular $\left[\mathrm{Mg}^{++}\right]$can also be increased by $\mathrm{Mg}^{++}$binding-promoting peptides.

If, as proposed, $\mathrm{Li}^{+}$, in psychiatric disorder, is actually critically acting in a lower than usual $\left[\mathrm{Mg}^{++}\right]$intracellular environment, the IMPase/IPPase, GSK-3, adenylate cyclase, etc., are then already limited to an extent suggested by their kinetics; it would take less potent activation of the PLCrelated receptor turnover to further enhance the existing 
background InsP-enhancement/inositol depletion, and less additional inhibition of the IMPase/IPPase derived from the added effects of $\mathrm{Li}^{+}$would be required; the mechanism could still be effective in cells subject to more realistic stimulation and show an enhanced selectivity, as $\mathrm{Li}^{+}$would have an even more remarkably selective, more powerful effect, in "low $\left[\mathrm{Mg}^{++}\right]$" cells.

The combined inhibition of lithium, combined with an initially low cell $\left[\mathrm{Mg}^{++}\right]$, would suggest that unexpectedly powerful levels of InsPhosphate enhancement/inositol depletion, and GSK-3 inhibition, could be attained (due to the GSK-3, IMPase and IPPase potentially being simultaneously inhibited by both factors), requiring more realistic levels of inositol turnover - ie, with $\mathrm{Li}^{+}$, selectively "working harder" in the most severely affected cells - creating potentially higher InsP1/P2 levels (and also, potentially higher galactose-P levels [see the 'Lithium's inhibition of PGM' section]) and a higher degree of inositol depletion (and membrane PI/PIP2 depletion) than suggested by previous in vitro models, examining the effects of $\mathrm{Li}^{+}$in cells with normal levels (or in vitro, quite often, actually rather higher than normal cell $\left[\mathrm{Mg}^{++}\right]$levels).

Higher levels of myo-inositol depletion, "InsP enhancement", would be expected in low intracellular free $\left[\mathrm{Mg}^{++}\right]$ systems. Berry et $\mathrm{al}^{79}$ claimed that even very severe myoinositol deficiency does not appear to adequately deplete membrane PI; yet, a low cell $\left[\mathrm{Mg}^{++}\right]$level does appear to cause a true membrane PI depletion, ${ }^{56,76}$ in cardiac muscle cells, so that perhaps the combined effect of $\mathrm{Li}^{+}$acting as proposed, within a low intracellular $\left[\mathrm{Mg}^{++}\right]$environment, may enable a true local (membrane) PIP2 depletion effect, as also further strongly implied by the TRPM7- $\mathrm{Mg}^{++}$-related evidence (see 'Inositol depletion provides a possible additional specific fail-safe action, limiting $\mathrm{Mg}^{++}$ion channels. Membrane PIP2 depletion acts on PLC and TRPM7, $\mathrm{a} \mathrm{Mg}^{++}$/ $\mathrm{Ca}^{++}$ion channel that can critically mitigate against $\mathrm{Ca}^{++}$ overload' section) (Figure 2).

\section{The magnesium abyss: critically low intracellular $\left[\mathrm{Mg}^{++}\right]$, metabolic crisis, the signaling and the proposed limiting of TBI}

In rodents, brain mean cell $\left[\mathrm{Mg}^{++}\right]$drops $50 \%-60 \%$, from $0.6 \mathrm{mmol} / \mathrm{L}$ to $0.25-0.3 \mathrm{mmol} / \mathrm{L}-$ as low as $0.2 \mathrm{mmol} / \mathrm{L}$, following brain injury - the mechanism of this reduction remains somewhat mysterious. Vink et $\mathrm{al}^{33,34}$ noted the decline in cell $\left[\mathrm{Mg}^{++}\right]$after head injury was associated with the development of neurological deficits. Magnesium administration prior to injury attenuates the damage. The decline in local $\left[\mathrm{Mg}^{++}\right]$was limited to the injury zone; this reduction in the cell $\mathrm{Mg}^{++}$concentration appears to be a specific indicator of cell damage, in all species and in all brain damage models; cell free $\left[\mathrm{Mg}^{++}\right]$concentration dropped by $40 \%-60 \%{ }^{33,34}$

This drop in intracellular $\left[\mathrm{Mg}^{++}\right]$seems to be a ubiquitous feature of brain injury, whatever the cause. ${ }^{33,34}$ However, the cell $\left[\mathrm{Mg}^{++}\right]$level never drops below a basal level of some $0.2-0.25 \mathrm{mmol} / \mathrm{L} .^{33,34}$ This decline typically persists for at least 4 days after TBI and with increasing severity of injury up to 7 days. ${ }^{33,34}$ Such a drop in the context of cell damage appears highly paradoxical as the electrochemical equilibrium potential for cellular free $\left[\mathrm{Mg}^{++}\right]$is much higher $-50 \mathrm{mM}$ in most mammalian cells. ${ }^{80}$

TBI does not appear to need to involve any actual brain ischemia, ${ }^{81,82}$ yet involves a complex, severe metabolic crisis, with a reduction of oxidative metabolism, thought to be due to a $\mathrm{Ca}^{++}$-mediated impairment of mitochondrial respiratory function, a short-lived increase in glucose utilization, low oxygen extraction, increased lactate production, a tendency to induce secondary cytokine release, etc. ${ }^{82,83}$ Mild head injury is difficult to avoid; there is evidence that it occurs even with "normal" birth.

It is not known how intracellular $\left[\mathrm{Mg}^{++}\right]$drops so precipitously after $\mathrm{TBI}^{33,34}$ (unionized cell $\mathrm{Mg}$ also drops to $10 \%-15 \%$ ), ie, what compounds might bind an increased proportion of $\mathrm{Mg}^{++}$, under these circumstances? As one of the main $\mathrm{Mg}^{++}$binding agents is ATP (and the ATP concentration is expected to drop after this type of event ${ }^{82}$ ), and hence tend to encourage an increase in ionized cell free magnesium, the depletion of cellular ATP by anoxia or other mechanisms, removing a large amount of ATP-related $\mathrm{Mg}^{++}$chelation, usually results in an increase in intracellular $\left[\mathrm{Mg}^{++}\right] .{ }^{26}$ Yet, paradoxically, post TBI, the cell $\left[\mathrm{Mg}^{++}\right]$ drops to a very low level ${ }^{33,34}$ in these critical conditions, involving an impairment of mitochondrial function. ${ }^{81,82}$ Alternative or additional $\mathrm{Mg}^{++}$-binding agent(s) may enter the picture. A few key glycolytic enzymes are activated by low $\left[\mathrm{Mg}^{++}\right]{ }^{83}$ in the post TBI situation, these enzymes might need to be maintained.

\section{Phosphoribosyl pyrophosphate; 5-phospho-D-ribosyl-} I (a)-pyrophosphate (PRPP)

\section{A key linking molecule}

Depletion of cell ATP can result in a remarkable increase in PRibosePP ${ }^{84}$ in some circumstances, an 80 -fold increase. PRPP synthase is subject to complex regulation, sensitive to $\mathrm{Pi}$ and $\left[\mathrm{Mg}^{++}\right] \cdot{ }^{84-87}$ Phosphoribosyl pyrophosphate is a $\mathrm{Mg}^{++}$ chelating agent. ${ }^{84,85}$ Its sugar phosphate structure suggests that it is another likely substrate for the IMPase. 


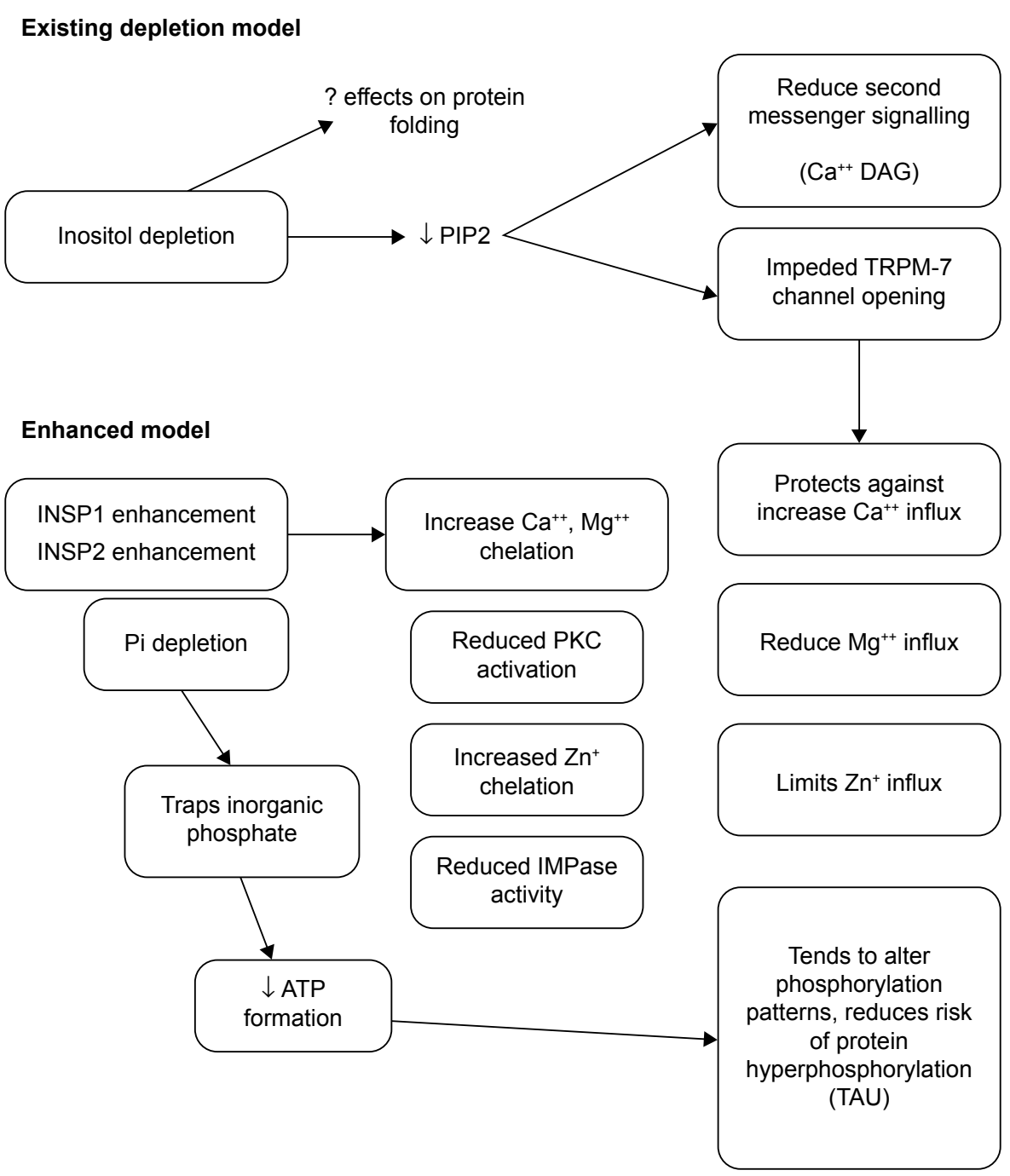

Figure 2 The role of inositol phosphate enhancement.

Notes: Blockade of inositol cycle by $\mathrm{Li}^{+} \pm$low cell $\left[\mathrm{Mg}^{++}\right]$leads to inositol phosphate enhancement. This traps inorganic phosphate and increases cell $\mathrm{Mg}^{++}$chelation tightening the inhibition of the IMPase/IPPase due to a lower cell $\left[\mathrm{Mg}^{++}\right]$environment. Also limits rises of $\mathrm{Ca}^{++}$by binding $\mathrm{Ca}^{++}$spikes and increases $\mathrm{GSK}-3$ inhibition.

Abbreviations: IMPase, inositol monophosphatase; IPPase, inositol polyphosphate-I-phosphate; GSK-3, glycogen synthase kinase 3; Pi, inorganic phosphate.

The formation of PRPP generates AMP and consumes ribose-5P and ATP. Consumption of ribose-5P will tend to stimulate the PPP.

PRPP synthase has been linked to the actions of $\mathrm{Li}^{+}$and valproate in yeast models. ${ }^{88}$ Yeast PRPP synthases appear to interact with GSK-3 ${ }^{88}$ In yeast, the structurally intriguingly similar Ins-pyrophosphates regulate mitochondria and ATP formation. ${ }^{89}$

PRPP is a biosynthetic precursor of GTP, riboflavin, and tryptophan; it is essential, and limiting, for both the de novo and the salvage pathways of purine, pyrimidine, and pyridine (NAD+, NADP+) nucleotides, ${ }^{83-87,90-92}$ so that PRPP availability will influence NAD availability, as well as affecting the availability of related (including potentially excito-toxic) tryptophan products. ${ }^{93}$
The tryptophan product and, NAD precursor, quinolate can induce poly (ADP-ribose) polymerase (PARP) activation with subsequent intracellular NAD+ depletion and reduced ATP levels, leading to negative effects of mitochondrial permeability and overproduction of superoxide and nitric oxide. ${ }^{93-97}$ NAMPT provides circadian rhythm control of NAD+ formation. PRPP is utilized to "detoxify" quinolate to nicotinate mononucleotide, and a reduction of this enzyme activity may contribute to seizures. ${ }^{98}$

The important observation that mild TBI enhances receptor coupling, increases muscarinic-linked inositol phosphate production, in rat hippocampus, ${ }^{99}$ helps explain and vividly mirrors Berridge's original critical observation that $\mathrm{Li}^{+}$amplifies the formation of inositol phosphates. ${ }^{2}$ The utility of the Delahunty paper ${ }^{99}$ is limited, as there was no $\mathrm{Li}^{+}$-free control 
used. Brain slices have a previously unexplained propensity to exhibit exaggerated Ins-P responses in response to $\mathrm{Li}^{+100}$ - this may reflect the mechanical cell injury during the preparation. Post TBI, a consequent very low cell $\mathrm{Mg}^{++}$could exhibit a $\mathrm{Li}^{+}$-like limiting action on the IMPase and would be expected to increase InsP levels. It predicts that the low cell $\left[\mathrm{Mg}^{++}\right]$ in conditions of fast turnover could have a similar effect in amplifying the "InsP signal" by significantly limiting the IMPase (and IPPase) activity, potentially demonstrating that TBI, by severely limiting the availability of cell $\left[\mathrm{Mg}^{++}\right]$could activate a form of acute $\mathrm{Li}^{+}$-like cell protection.

It is not clear whether this acute drop in cell $\left[\mathrm{Mg}^{++}\right]$(post $\mathrm{TBI})^{33,34}$ is an "unavoidable" response, eg, perhaps aggravated by membrane depolarization. The TBI involves a high degree of $[\mathrm{ATP}]$ depletion; the drop in cell $\left[\mathrm{Mg}^{++}\right]$gives the appearance of providing an active signal to mobilize "cell injury" responses to promote cell survival, tending to de-activate lessessential activity, facilitate repair including increasing purine salvage, and perhaps dampening apoptotic mechanisms, etc.

Polyamine levels also increase in what Gilad and Gilad ${ }^{101,102}$ term a programmed, "universal" biochemical response to TBI Polyamines, possessing multiple positive charges, might be able to substitute for $\mathrm{Mg}^{++}$ions in some situations. Polyamines modulate RNA and chromatin structure; ${ }^{103,104}$ RNA folding is very sensitive to $\left[\mathrm{Mg}^{++}\right]$concentration, ${ }^{103}$ and polyamines also co-chelate with ATP. ${ }^{105}$

A low intracellular $\left[\mathrm{Mg}^{++}\right]$in the early phases of an acute brain injury might shut down non-essential aspects of metabolism to conserve energy in a special situation, where normal mitochondrial, Ox-Phos, and ATP production is challenged, and would also tend to restrict cAMP dependent cell signaling, and by binding $\mathrm{Ca}^{++}$(which is increased after ATP depletion ${ }^{105}$ ), tend to limit $\mathrm{Ca}^{++}$dependent PKC-DAG signaling, and perhaps somewhat limiting calcium release via the InsP3R as this requires a coincident $\mathrm{Ca}^{++}$signal, and via inositol depletion, and consequent membrane PIP2 depletion, and potentially further limit excito-toxic signaling, etc.

As the cell free $\mathrm{Mg}^{++}$drops, the IMPase/IPPase (and GSK-3) activity will tend to become further limited by the lack of $\mathrm{Mg}^{++}$; in the case of the IMPase/IPPase, assuming a sufficient level of turnover, more InsP is produced, which will tend to deplete $\mathrm{Pi}$ and chelate and bind the remaining cell $\mathrm{Mg}^{++}$, tightening the inhibition of the IMPase/IPPase/ GSK-3 further (in a positive feedback loop), and tend to chelate any excess cell $\mathrm{Ca}^{++},{ }^{51,52} \mathrm{Zn}, \mathrm{Fe}, \mathrm{Cu}$ ions, etc., ${ }^{60}$ toxic/ regulatory metal ions, potentially limiting secondary free radical formation.

\section{Is there enough $\mathrm{Mg}^{++}$buffering?}

Depletion of ATP can result in a remarkable increase in PRPP ${ }^{84,85}$ (another $\mathrm{Mg}^{++}$chelating agent) in some circumstances, an 80-fold increase (in liver cells) to $\sim 480-580 \mu \mathrm{mol} / \mathrm{L}$; this could provide the required shortterm additional background $\mathrm{Mg}^{++}$buffering. Thus, InsP would initially not need to bind more than a small fraction of the total cell $\mathrm{Mg}^{++}$; even a modest initial neuronal cell inositol concentration of, say, 50-100 $\mu \mathrm{mol}$, rendered into InsPhosphate (and/or the "bidentate" InsP2), etc., could then usefully collectively help to suppress the cell $\left[\mathrm{Mg}^{++}\right]$toward the basal $0.25 \mathrm{mmol} / \mathrm{L}$, with potentially a further decrease in final cell $\left[\mathrm{Mg}^{++}\right]$concentration - a consequently tighter degree of IMPase/IPPase, GSK-3, and adenylate cyclase inhibition.

This may explain the remarkable findings of Sherman et $\mathrm{al}^{106}$ that in rat brain, the concentration of InsP continues to rise to $4.43 \pm 0.52 \mathrm{mmol} / \mathrm{kg}$ (dry weight) compared with a control level of $0.24 \pm 0.02 \mathrm{mmol} / \mathrm{kg}$ over up to 9 days after initiation of lithium; is the system, eg, post TBI, continuing to help "clamp" the intracellular $\left[\mathrm{Mg}^{++}\right]$, so as to continue to maintain the "cell protection signal", during the critical first few days of the early TBI repair phase; This also binding the equivalent inorganic phosphate, $\mathrm{Pi}$, the formation of Ins-P also limiting the rise, and the extrusion of cell $\mathrm{Mg}^{++}$, helping to limit any rise of extracellular $\left[\mathrm{Mg}^{++}\right]$, and perhaps also having a useful osmotic effect equivalent to sequestering at least $4 \mathrm{mmol} / \mathrm{L}$ Pi not counting any additional InsP2 - a "bidentate" chelating agent, also formed.

Inositol has been construed as having an osmoregulatory role; potential osmotic benefits against the brain cell swelling post head injury could be derived by binding more phosphate to alternative sugars, including FBP, and the increased formation of astrocytic glycogen, also tending to lower the local intracellular molarity. Piron et al ${ }^{107}$ have shown that $\mathrm{Mg}^{++}$contributes significantly to osmoregulation, modulating ion channel-PIP2 interactions. Low extracellular glucose post head injury ${ }^{108}$ is associated with poor outcome; however, increased glycogen formation has been demonstrated post head injury; this may provide evidence of TBI acting to reduce GSK-3 activity; in spite of the lower cell energy availability, TBI manages to increase the astrocytic glycogen formation. ${ }^{109}$

Most brain inositol is in glia/astrocytes; yet, there is still the "expected" (if the starting point is $50 \mu \mathrm{mol}$ - up to an impressive 80 or so times) rise in (presumably) mainly neuronal InsP1, post $\mathrm{Li}^{+}$, in whole rodent brain. ${ }^{106}$ This tends to argue against "depletion", as the sole or dominant mechanism. If the initial inositol concentration - in the relevant 
neurons - is $\sim 50-100 \mu \mathrm{mol}$, in the rat, InsP1 can over a few days rise to $4.4 \mathrm{mmol} / \mathrm{L},{ }^{106}$ also reflecting a significant shift in a finite pool of cell Pi, implying a strong cell [Pi] depletion if the de-phosphorylation is blocked by $\mathrm{Li}^{+}$and if there is sufficient agonist drive - "fast turnover". Human brain inositol concentration - mainly non-neuronal - is $\sim 9 \mathrm{mmol} / \mathrm{L} .{ }^{110}$

In spite of the experimental evidence concerning the neuroprotective effects of magnesium, ${ }^{33-35}$ a trial of magnesium in patients with moderate or severe TBI was unable to show neuroprotective effects and even indicated a possibility of harm. ${ }^{111}$ There is no lack of total magnesium in this situation, consistent with the idea that the low cell $\left[\mathrm{Mg}^{++}\right]$may be used as a trigger; an alarm signal to activate a set of protective responses, the depletion of cell $\mathrm{Mg}^{++}$occurs paradoxically in the face of much reduced ATP production. ${ }^{82,83}$

Magnesium has been proposed to be effective in TBI; ${ }^{35}$ it inhibits a number of the secondary injury factors..$^{20,33-35}$ Nicoletti et al ${ }^{112}$ demonstrated a 6-8-fold increase in Ins-1-P accumulation in conditions of low $\left[\mathrm{Mg}^{++}\right]$.

TBI involves a mixture of mechanical damage, excitotoxicity, oxidative stress, inflammation, ATP depletion, and the depletion of the NAD+-type, co-enzyme pool, mitochondrial dysfunction and $\mathrm{Ca}^{++}$overload, secondary cytokine release, etc. ${ }^{81,82}$

Any post TBI repair system is a compromise evolved without the luxury of extra pre/post-treatment $\mathrm{Mg}^{++}$available. Giving additional $\mathrm{Mg}^{++}$, at the correct phase, might relieve some pathways that are otherwise needlessly limited. Perhaps, combining $\mathrm{Mg}^{++}$pre/post-treatment with lithium ( \pm galactose) might perhaps potentially provide enhanced protection. The optimal actions are likely to vary with time as different repair mechanisms set in. Given the apparent biochemical sophistication of the proposed mechanisms, it is unsurprising that it has proved difficult to demonstrate more effective treatments in human $\mathrm{TBI} ;{ }^{111} \mathrm{Li}^{+}$protects against stroke and predictably is protective against TBI in mice. ${ }^{113}$

\section{Brain insults as backdrops to mood disorder}

The apparent potential for a sudden drop in cell $\mathrm{Mg}^{++}$levels to occur after TBI may be a more extreme case, utilizing the general mechanism, which may also operate less dramatically in the more chronic situation of a compromised cell $\left[\mathrm{Mg}^{++}\right]$, tending to be associated with mitochondrial dysfunctions, which appear associated with a degree of cell ATP depletion and lower cell [ATP-Mg] levels (see 'The magnesium abyss' section).

Brain cells may regulate their cytosolic free $\left[\mathrm{Mg}^{++}\right]$as a function of the energy charge of the cell. Reduced ATP formation can occur with hypoxia, or other insults, including chemical injury. A lower cytosolic free $\left[\mathrm{Mg}^{++}\right]$occurs in patients with mitochondrial disease; this appears related to a relative failure of the respiratory chain. Lowered ATP and creatine kinase activity and lower creatine levels have been linked to depression. ${ }^{114}$ There appears a lower cell energy, lower ATP, in depression. ${ }^{18}$ Bipolar disorder is thought to reflect a form of mitochondrial dysfunction. ${ }^{115-117}$ Hypoxia/ ischemia can induce mitochondrial free radical production; during ischemia, the kynurenine pathway is activated, leading to increased production of quinolinic acid. ${ }^{94,95}$

Mania has been reported after correction of sleep apnea. ${ }^{118}$ Anxiety and psychosis are more common in individuals with sleep apnea. ${ }^{119}$ White matter lesions observed in depression and bipolar disorder may provide evidence for ischemia or reperfusion damage. ${ }^{12}$ Possible re-perfusion injury is suggested by migraine occurring in a high proportion of patients with bipolar; reperfusion injury resembles migraine - a condition claimed to be associated with low brain $\left[\mathrm{Mg}^{++}\right]$.

Kato et al ${ }^{116}$ suggested mitochondrial dysfunction associated with genetic changes in mood and related disorders. $\mathrm{Mg}^{++}$is critical to mitochondrial function, as $\mathrm{Mg}^{++}$complexes with ATP and stimulates the entry of important substrates into brain mitochondria; the availability of Pi affects mitochondrial $\mathrm{Mg}^{++}$concentrations. ${ }^{120,121}$ Other causes of relative cell [ATP] depletion in mood disorders include factors increasing ROS, tending to deplete NAD+, NADPH, and GSH (reduced glutathione). Endotoxins and similar factors have the potential to derange mitochondrial electron transport, leading to disordered energy metabolism, even when enough oxygen is present. The degree of ATP and NAD+ impairment is likely to be less severe, but perhaps more long term in mood disorders, than post TBI, or following stroke, etc.

Reduced NAD+ availability induces a "pseudo-hypoxic" state $^{122}$ that contributes to a decline in mitochondrial function with age. Factors limiting the formation or depleting NAD will tend to deplete ATP, as NAD availability is required and appears limiting for mitochondrial ATP formation; eg, in circumstances where glucose is the main substrate, depletion of cytoplasmic NAD by $50 \%$ or more can block glycolysis and mitochondrial substrate flux. ${ }^{123}$

The IMPase and IPPase are both severely limited at this basal $(0.25 \mathrm{mmol} / \mathrm{L})$ level of intracellular $\left[\mathrm{Mg}^{++}\right]$; this potentially also more fully inhibits GSK-3 and more intensely tends to result in inositol depletion/inositol phosphate enhancement and inorganic phosphate (Pi) depletion, progressively creating a little extra (reasonably high-affinity) $\mathrm{Mg}^{++} /\left(\mathrm{Ca}^{++}\right)$chelation buffering. This would - if turnover is 
sufficient - then tend to chelate $\mathrm{Ca}^{++}$and more of the remaining available cell $\mathrm{Mg}^{++}$, tending to trap both the cell $\left[\mathrm{Mg}^{++}\right]$ and $\mathrm{Pi}$ and to pull the intracellular inositol concentration (and the postulated small "active pool") of membrane PI/ PIP2 downwards, simultaneously tightening the inhibition of the IMPase, IPPase, and GSK-3, etc., in a positive feedback loop-optimizing cell protection.

A relatively large pool of intracellular neuronal InsP can accumulate. ${ }^{106} \mathrm{Li}^{+}$appears more effective at reducing elevated mood than lifting a low mood - the proposed mechanism suggests that the initial effect in increasing InsP is at first to clamp to lower the cell $\left[\mathrm{Mg}^{++}\right]$and limit cell $\left[\mathrm{Ca}^{++}\right]$, and sequester $\mathrm{Pi}$; this action is seemingly more protective than any early small increase in cell $\left[\mathrm{Mg}^{++}\right]$might be. Only subsequently when Ins-P levels drop, would the cell $\left[\mathrm{Mg}^{++}\right]$ level then tend to rise alongside the [ATP], and the system's protective effects decline as intracellular $[\mathrm{ATP}],\left[\mathrm{Mg}^{++}\right]$, and $\left[\mathrm{Ca}^{++}\right]$normalizes.

This suggests that $\mathrm{Li}^{+}$may have subsequent slower, "ratchet-like" actions that may subsequently tend to help normalize the cell $\left[\mathrm{Mg}^{++}\right]$, once cell function returns to normal releasing inositol, $\mathrm{Mg}^{++} / \mathrm{Ca}^{++}$, and $\mathrm{Pi}$, with the lysis of Insphosphates. Although initially construed as a mechanism to protect against conditions of a low cell $\left[\mathrm{Mg}^{++}\right]$, this is perhaps better construed as low cell [ATP] conditions associated with a low cell $\left[\mathrm{Mg}^{++}\right]$.

The accumulation of InsP will also clamp, limits subsequent rises in cell $\left[\mathrm{Mg}^{++}\right]$and by binding finite, limited amounts of cell [Pi], with effects on PPi exerting a potential shift in cell-protein phosphorylation patterns, and/or tending to limit the rate and amount of high energy phosphate formation, ${ }^{124-126}$ potentially limiting mania, assuming mania may reflect a higher cell-energy level. The sequestration of $\mathrm{Pi}$, eg, during the formation of galactose-1-phosphate in galactosemia, can limit ATP formation. ${ }^{124}$

Presumably, the details of these mechanisms, including actions via cAMP, help to facilitate the longer-term restoration of both the cell $\left[\mathrm{Mg}^{++}\right]$and $[\mathrm{ATP}]$ concentrations. Lowering of cell [Pi] tends to promote breakdown of AMP toward uric acid, tending to increase adenosine, which is protective in its own way.

These proposed protective mechanisms would mitigate the downstream effects that would occur on systems related to the control of mood: mitochondria, enzymes, ATP/ADP, adenosine, ion channels, ATPases, G-proteins, cAMP, and perhaps other proteins, particularly peptides; factors with delicate folding requirements were subject to relatively unrestrained swings of cell $\left[\mathrm{Mg}^{++}\right]$concentration, including the potentially "arresting" effects of phases of critically low cell $\left[\mathrm{Mg}^{++}\right]$levels, likely to coincide with conditions of altered levels of cell [ATP], and also potentially associated with various forms of "traumatic cell injury"; this suggests that overall $\mathrm{Li}^{+}$may ultimately act by utilizing systems primarily geared to mitigate the effects of low cell $\left[\mathrm{Mg}^{++}-\mathrm{ATP}\right]$ related to TBI. $\mathrm{Mg}^{++}$strongly stabilizes tertiary structures in a "free-energy", polyamine and in a [Pi] concentrationsensitive fashion. ${ }^{104}$

Inositol depletion provides a possible additional specific fail-safe action, limiting $\mathrm{Mg}^{++}$ion channels. Membrane PIP2 depletion acts on PLC and TRPM7, a $\mathrm{Mg}^{++} / \mathrm{Ca}^{++}$ion channel that can critically mitigate against $\mathrm{Ca}^{++}$overload

PLC has always been the putative "target" of the original inositol depletion model. ${ }^{1,2}$

PLC has always been conceptualized as providing a common pathway for cell signaling by the postulated hydrolysis of a small active pool of membrane phosphatidylinositol4,5-bisphosphate (PtdInsP2) (PIP2), providing a dual output, InsP3, and a second associated DAG signal. There is a potential additional "third signal", the potential for the inactivation of TRPM7 - an important $\mathrm{Mg}^{++}$ion channel ${ }^{26,127-129}$ - which may be another potential further target of $\mathrm{Li}^{+}$action. PLCbeta, a signaling enzyme, ${ }^{26,127-130}$ which utilizes the membrane PIP2 that would tend to be limited during inositol depletion, is directly coupled to TRPM7, ${ }^{26,128,130,131}$ which is a key $\mathrm{Ca}^{++}$ and $\mathrm{Mg}^{++}$ion channel that during excito-toxicity, seems essential for mediating $\mathrm{Ca}^{++}$overload and to have a central role in both excito-toxic and non-excito-toxic neuronal death mechanisms, a broader protective role than protecting against just NMDA-mediated excito-toxicity. ${ }^{26,128,129,131,132}$

This suggests that inositol depletion, rather than just limiting PLC-related receptor-based second messenger mechanisms, might potentially also act by also limiting associated $\mathrm{Mg}^{++}$(and $\mathrm{Ca}^{++}$)-related PIP2-dependent, PLC-coupled ion channels, which may provide additional mechanisms of further intrinsic protection related to (notionally) NMDA receptor-linked excess glutamate activity, but possibly actually mediated by a further related parallel $\mathrm{Ca}^{++}$and trace metal (perhaps including a zinc ion entry system). ${ }^{26,133}$

TRPM7 is an $\mathrm{Mg}^{++}$ion channel, an enzyme, a serine/ threonine kinase, and an "alpha kinase", related to eEF2 kinase $^{26,129,130,133,134}$ (required for cell survival under acute nutrient deprivation). ${ }^{92,130}$ eEF2 kinase is activated by AMP kinase and also appears linked to BDNF and to the action of ketamine in lifting mood. ${ }^{134,135}$ 
TRPM7 has a functional role in survival under hypoxia or re-perfusion. ${ }^{26,127-129,131}$ The kinase domain directly associates with the C2 domain of PLC. ${ }^{130}$ This further links both the inositol depletion and "InsP enhancement" sub-mechanisms, to limit NMDA/glutamate-related excito-toxicity and the related free radical formation, an apparent vital common pathway in the origins of "psychosis".

TRPM7 activation is increased by ROS; its activity is promoted both by anoxia and excito-toxicity. ${ }^{36,131,132}$ The inactivation of TRPM7 protects from $\mathrm{Ca}^{++}$overload and prolonged anoxia; intact TRPM7 function seems to be essential to mediate $\mathrm{Ca}^{++}$overload and consequent cell death.

This TRPM7-mediated $\mathrm{Ca}^{++}$overload has been proposed to represent an essential component mechanism of excitotoxic cell death, associated with the "classical" NMDAglutamate mechanism (yet this appears to be a rather more complex mechanism), one that seems parallel to and which appears "dominant" to the "classical" pathway. ${ }^{26,127,129-132}$ The activation of TRPM7 requires a physiological level of $\left[\mathrm{Mg}^{++}\right]$, and reducing the cell $\left[\mathrm{Mg}^{++}\right]$concentration - with a suitable "chelating agent" $" 129$ - results in a PLC-mediated inactivation of TRPM7, which appears mediated by a PIP(2) depletion. ${ }^{26,126,128,130}$

TRPM7 gating is downstream from NMDA, NO, and peroxynitrate-mediated free radical formation; TRPM7 suppression thus protects widely against a hazardous feedback loop involving $\mathrm{Ca}^{++}$influx and ROS. ${ }^{26,128-131}$

The proposed "TRPM7 channel depletion" mechanism would complement the protection provided by $\mathrm{Ca}^{++} / \mathrm{Mg}^{++}$ chelation due to the "enhancement" of InsPhosphate and/ or ("equivalent") sugar phosphates; these also increase in conditions of excess $\mathrm{Ca}^{++}$loading and consequent increased free radical formation due to changes in the flow of glucose toward the formation of PPP-derived metabolites.

An increased total cell metal chelation capacity will tend to further limit intracellular $\left[\mathrm{Ca}^{++}\right]$and $\left[\mathrm{Mg}^{++}\right]$concentrations via (at least) two mechanisms: severe limitation of $\mathrm{Ca}^{++}$and $\mathrm{Mg}^{++}$entry, due to inactivation of the TRPM7 channel and due to depletion of a pool of active membrane PIP2, ${ }^{126,128,130}$ and increased cellular free radical damage, due to excess $\mathrm{Ca}^{++}$entry ${ }^{131}$ and via increased cation chelation. This would combine to limit excess cell $\mathrm{Ca}^{++}$and reduce the level of cell $\left[\mathrm{Mg}^{++}\right]$available to activate the IMPase, IPPase, GSK-3, etc., limiting their activity and reinforcing the inositol depletion and membrane PIP2 depletion (in a triple positive feedback loop) (as an increase in Ins-P, and/or sugar phosphates/ or Gal-P, will also tend to further increase inhibition of the IMPase/IPPase by increasing the IMPase substrate inhibition) - as these sugar phosphates, including galactose$\mathrm{P},{ }^{124}$ are also further competing IMPase substrates.

\section{A non-linear system, low cAMP helps the restoration of cell $\left[\mathrm{Mg}^{++}\right]$levels}

The IMPase is a non-linear system; the IMPase enzyme is inhibited to a greater extent when substrate concentrations increase; thus when turnover rate is most rapid. If cell $\left[\mathrm{Mg}^{++}\right]$ drops the IMPase (and eventually the IPPase) starts to become limiting (also in a non-linear fashion) at some point as turnover increases; this has the effect of increasing inositol-P1/(and InsP2) levels; this has effect of binding more $\mathrm{Mg}^{++}$; "paradoxically" tending to further suppress the cell $\left[\mathrm{Mg}^{++}\right]$, and limit cell $\left[\mathrm{Ca}^{++}\right]$, at the same time increasing the cell's $\mathrm{Mg}^{++} \mathrm{Ca}^{++}$ and total binding capacity (including various downstream membrane bound $\mathrm{Mg}$ binding derivatives); the action being to appear at first to magnify the cell $\left[\mathrm{Mg}^{++}\right]$"deficiency", perhaps this ultimately stimulates a compensatory inwards flux of $\mathrm{Mg} / \mathrm{Mg}^{++}$, or flux of $\mathrm{Mg}^{++}$between cell organelles and the cytoplasm. This, as in the TBI situation, appears paradoxical, as apart from increasing the total cell Mg-binding capacity and total cell $\mathrm{Mg}$ content, it will initially tend to further actively pull down and clamp the cell $\left[\mathrm{Mg}^{++}\right]$and $[\mathrm{Pi}]$ concentrations. The increased $\mathrm{Mg}^{++}$-binding capacity would help limit shortterm cell $\mathrm{Mg}^{++}$export and would also tend to clamp any rise of cell $\left[\mathrm{Mg}^{++}\right]$. It may create enough additional chelation to limit or lower cell $\left[\mathrm{Ca}^{++}\right]$and thus potentially limit the activation of certain $\mathrm{Ca}^{++}$-requiring forms of $\mathrm{PKC}$ and restrict the opening of TRPM7-type, $\mathrm{Mg}^{++}$ion channels. ${ }^{128}$

$\mathrm{Li}^{+}$(and/or a low cell $\left[\mathrm{Mg}^{++}\right]$) will also tend to limit the formation of cAMP (eg, via inhibition/restriction of the stimulatory unit of adenylate cyclase, which is aggravated by permitting greater inhibition via [unchelated] free ATP), a drop in cAMP would tend to increase the influx of $\mathrm{Mg} / \mathrm{Mg}^{++}$ into the cell; this would then tend to bind to the now increased $\mathrm{Mg} / \mathrm{Mg}^{++}$-binding capacity, perhaps increasing the size of the total ("inertial") pool of cell $\mathrm{Mg}^{++}$; reduced cAMP also tends to reduce ATP "wasted" by the $\mathrm{Na}+\mathrm{K}+$ ATPase.

Thus, a drop in cell $\left[\mathrm{Mg}^{++}\right]$(and/or $\mathrm{Li}^{+}$) if accompanied by a sufficient level of turnover proportionate to that cell $\left[\mathrm{Mg}^{++}\right]$ concentration (ie, resulting in sufficient InsP accumulation) while at first, as in the post TBI situation, actively suppressing the cell $\left[\mathrm{Mg}^{++}\right]$(and $\mathrm{Ca}^{++}$) concentration; this will over time potentially tend to be (over)-corrected for by actions of $\mathrm{Li}^{+}$(and/or a low $\left[\mathrm{Mg}^{++}\right]$) by limiting cAMP formation; this would help the eventual restoration, the "over"-correction of the $\left[\mathrm{Mg}^{++}\right]$concentration to the non-linear nature of the system. Clinical improvement appears to take place after 
the rise in InsP. Lithium and/or a low cell $\left[\mathrm{Mg}^{++}\right]$have the potential to simultaneously limit both PIP2-dependent and the cAMP-based signaling systems.

\section{Complexity and more "exotic" fail-safe mechanisms; lithium's inhibition of BPNase, PARP-I, PRPP, purines, NAD+, and ATP (Group 3)}

There is the possibility that the inhibition of the other enzymes with the same common core structure-BPNase and FBPase, at least in the post TBI situation - may also provide protection in conditions associated with a limiting, low cell $\left[\mathrm{Mg}^{++}\right]$. BPNase is both a 3'phosphoadenosine 5'-phosphate (PAP) phosphatase and an IPPase. ${ }^{21}$ Over-activation of PARP-1, eg, post conditions resembling TBI, such as stroke or high glucose levels, leads to depletion of $\mathrm{NAD}(+)$ and then to depletion of ATP, leading to a critical cell-energy deficit. ${ }^{136}$ Inhibition of the PAP phosphatase by lithium leads to increased levels of $\mathrm{pAp}\left(3^{\prime}-5^{\prime}\right.$ phosphoadenosine phosphate), which can inhibit PARP-1. ${ }^{137}$ This action of lithium (or a low cell $\left[\mathrm{Mg}^{++}\right]$), via limiting the BPNase, would help to prevent energy (ATP and NAD+) depletion.

PARP-1 and $\mathrm{Mg}^{++}$both help to maintain chromatin structure. ${ }^{138,139}$ PARP1, in turn, induces ADP ribosylation of GAPDH - an enzyme that consumes NAD+, leading to its utilization - inactivation (not just a change in redox state) and an accumulation of glycolytic metabolites earlier in the pathway (which could have effects on minor sugar phosphate levels). PARP-1 activity is known to induce NO production. ${ }^{140}$ Cerebral reperfusion injury induces GAPDH S-nitrosylation, ${ }^{141}$ itself linked to NMDA receptor activation, so that lithium's inhibition, or limitation of the BPNase, creating increased levels of PAP, limiting the action of PARP-1, as well as limiting cell energy depletion, may offer broader cell protective actions.

Factors limiting formation or depleting NAD will also deplete ATP, as NAD availability is limiting for mitochondrial ATP formation. Valproate inhibits histone deacetylases ${ }^{142}$ the inhibition of PARP-1 increases NAD enough to increase activity of SIRT1; sirtuins also use NAD to mediate deacetylation and ADP ribosylation,,$^{94,96,97,143-146}$ so that the inhibition of deacetylases will also be able to modulate the availability of NAD+ and hence influence cell ATP supplies.

The first step in NAD+ synthesis is the formation of nicotinate ribonucleotide - from nicotinate and PRPP. PRPP also functions in several other ribosylating reactions.

The NAD+ precursor, and potent SIRT-1 inhibitor nicotinamide, ${ }^{143}$ prevents NAD+ depletion and attenuates excito-toxic neuronal cell death. Irreversible NAD consumption by PARP-1 and SIRT1 may endanger energetically compromised neurons under conditions of reduced cell energy. SIRT1 may utilize enough $\mathrm{NAD}^{146}$ to nullify any survival advantage from its deacetylase activity. PARP and sirtuin enzymes compete for the common NAD+ substrate; various key enzymes in the NAD+ salvage pathway regulate SIRT-1 activity. ${ }^{97,146,147}$

Increased PP-Ribose-P, in enhancing purine salvage pathway activity, would help to preserve NAD+ and hence help protect cell [ATP] levels.

\section{Relationship to the mode of action of valproate, PRPP and TBI}

Valproate, like nicotinamide and butyrate, is a histone deacetylase inhibitor; ${ }^{142}$ thus, valproate would help conserve both NAD and hence ATP during conditions where cell NAD becomes limiting. The conservation of NAD, and hence the preservation of cell [ATP], might be an important aspect of valproate's mode of action as a mood stabilizer.

$\mathrm{NADP}+$ is required ${ }^{148}$ for the formation of 4-hydroxybutanoic acid $(\mathrm{GHB})^{149}-\mathrm{GHB}$ can reduce energy substrate consumption, and this has been implicated in the mode of action of valproate. ${ }^{150}$

Zimmer $^{90}$ has shown that increasing the size of the tissue PRPP pool in rat heart, eg, using ribose, considerably increased the rate of restoration of cell [ATP] following various maneuvers, which decrease the ATP content; zur Nedden et $\mathrm{al}^{151}$ have shown that both ribose and adenine help to restore post brain injury cell [ATP]; adenine can improve basal ATP in brain slices; the activity of the purine salvage (PRPP-related) pathways contribute to this restoration of cell [ATP].

A lack of BDNF may contribute to depression. ${ }^{152}$ Inosine is an important adenosine breakdown product and can bypass BDNF receptors. Inosine can act post-synaptically, mimicking BDNF. ${ }^{134,135}$ This begins to explain why inosine, hypoxanthine, and nicotinamide possess endogenous benzodiazepine ligand-like properties. ${ }^{153}$ Inosine is formed extracellularly as a product of ATP breakdown. The loss of purines to the extracellular compartment risks the longlasting depletion of intracellular salvage metabolites, required to reform ATP; this again points to the importance of the salvage pathways in maintaining the long-term cell (ATP) levels; PRPP plays a key role in these salvage pathways. ${ }^{90}$

Factors limiting the waste of NAD or its precursors - such as proposed here $\mathrm{Li}^{+}$, valproate, and creatine - would thus help support long-term cell energy (ATP-Mg) levels. 
This may suggest that nicotinic acid and/or nicotinamide (the actions of which differ in detail), and perhaps adenine and ribose, might also have some potential valproate-like mood-stabilizing action. The situation in head injury, where PRPP (a precursor source of nucleotides) is formed in response to low ATP levels, enhancing pyrimidine salvage, ${ }^{88,143}$ helping to reduce potentially neurotoxic quinolate levels, is in stark contrast with that in cancer therapy, where after induction of a lowered cell [ATP] (induced by limiting NAD formation and/or by increasing the utilization of ATP by the activation of PARP), low [ATP] cell death is markedly enhanced by pyrimidine depletion, ${ }^{121}$ ie, the combined effect of the cellular survival response post head injury (or post- $\mathrm{Li}^{+}$) is opposite to that during attempts to kill cells using chemotherapy.

Nicotinamide is not only an NAD precursor and a product of sirtuin deacetylation ${ }^{143}$ but also both a SIRT1 and a PARP-1 inhibitor. ${ }^{96}$ Nicotinamide is a very effective deacetylase inhibitor. ${ }^{96}$ Nicotinamide thus both increases NAD formation and reduces NAD utilization. It also protects against excito-toxicity. NAD protects against the effects of stroke. ${ }^{96}$ Nicotinamide offers multiple protective mechanisms in stroke - as a precursor for NAD+, as a PARP inhibitor, and by partial restoration of mitochondrial function. ${ }^{96}$ Valproate, like $\mathrm{Li}^{+}$, also protects against the effects of $\mathrm{TBI}^{154}$ and cardiac anoxic damage.

This also further links PRPP to serotonergic mechanisms, as de novo NAD+ synthesis is via the kynurenine pathway, and the breakdown of tryptophan increases NAD, notionally via the formation of quinolinic acid. Human nicotinamide availability is often marginal. ${ }^{155}$ Shibata et al ${ }^{155}$ demonstrated an increase in nicotinamide formation due to increased tryptophan breakdown induced by valproate, in rats. ${ }^{155}$ Valproate has a further action in displacing tryptophan from plasma albumin; ${ }^{156}$ this increases central kynurenic acid and tryptophan levels. ${ }^{156}$ Valproate also increases liver NAD concentration. ${ }^{155}$ Other short-chain fatty acids, 3-hydroxybutyrate, acetoacetate, and dietary fats, similar to valproate also increase central tryptophan levels ${ }^{157}$ - displacing it from plasma albumin ${ }^{147}$ and increasing tryptophan breakdown, to form more nicotinamide.

5HT re-uptake inhibitors reduce waste of 5HT precursors, so they might in part lift mood by an additional mechanism, enabling more NAD and related products such as nicotinamide to accumulate. Increased uric acid levels have been demonstrated in mania; this appears to be a true state marker for mania. ${ }^{158}$ Lower serum phosphate levels have been found during anxiety and depression. ${ }^{125}$ An adequate blood phosphate, [Pi], level is required to maintain normal ATP metabolism. ${ }^{126}$

Valproate, broadly mimicking a ketone body, by increasing nicotinamide formation from tryptophan, and limiting NAD consuming deacetylation reactions, would improve the NAD supply and hence tend to reduce the risk of [ATP] depletion.

Extracellular adenosine levels can rise after various metabolic stresses. ${ }^{159}$ Adenosine can be released preemptively when there is a risk of ATP consumption outstripping ATP production; ${ }^{159}$ the activation of adenosine receptors by the release of ATP activates A1 receptors, which helps reduce cell excitability to prevent potentially excessive energy demand arising. Carbamazepine may uprate adenosine A1 receptors. ${ }^{160}$ Carbamazepine also tends to reduce cell cAMP concentrations. ${ }^{161,162}$

Preempting a cell energy crisis may be an alternative strategy. Carbamazepine could help prevent potentially overstimulated cells from becoming critically energy-depletednot because of excess PARP-1 and sirtuin-related, excess NAD utilization, but by limiting excessive "fast-firing" activity, and by reducing cAMP formation, ${ }^{161}$ helping to restore cell $\left[\mathrm{Mg}^{++}\right]$. Valproate also has actions that include lowering of cAMP; a low cAMP tends to help restore intracellular $\left[\mathrm{Mg}^{+}\right] \cdot{ }^{34,163}$ Lithium, CBZ, and valproate all eventually produce an increase in cell $\left[\mathrm{Mg}^{++}\right]$levels. ${ }^{164}$

\section{More exotic protection; the potential protective role of the inhibition of FBPase post TBI (Group 4)}

FBPase is usually construed as involved in gluconeogenesis; surprisingly, increased glycogen formation has been demonstrated post head injury, ${ }^{108,109}$ so that gluconeogenesis could still occur in (delayed) phases of such situations. FBP is an endogenous cell protective molecule; it facilitates recovery during hypoxia and ischemia and helps to stabilize intracellular $\mathrm{Ca}^{++} \cdot{ }^{165} \mathrm{FBP}$, a diffusible high-energy intermediate, is protective in many different systems. ${ }^{165,166}$ This cyto-protective activity has been described in many systems - reperfusion injury, sepsis, etc. ${ }^{167,168}$

Relating to the previous comments about PARP-1, as already noted, increased NO production inhibits GA3PDH via S-nitrosylation or by ADP ribosylation; this can modify the rate of formation of glycolytic intermediates, which leads, eg, in the gut, to increased tissue FBP accumulation; NO generated during pre-conditioning inhibits GA3PDH and leads to NO-dependent FBP accumulation. Inhibition of FBPase by $\mathrm{Li}^{+}$will tend to increase levels of $\mathrm{FBP}$, particularly in conditions of increased NO production, such as post TBI.

FBP has strong anticonvulsant activity. ${ }^{167}$ Low glutathione (GSH) levels appear to be associated with seizures. ${ }^{158,169}$ $\mathrm{FBP}$, the precursor for glyceraldehyde-3P and DHAP, is an activator of the PPP and, by increasing synthesis of 6-phosphogluconate, activates the flow of G-6P to the PPP, 
helping to enhance NADPH formation to maintain GSH levels, and this tends to help raise seizure thresholds. ${ }^{167,169}$ FBP is also a chelating agent, binding $\mathrm{Ca}^{++}$and $\mathrm{Fe}$ (II).

FBP improves metabolic efficiency, can affect apoptosis and second messenger release, ${ }^{169}$ and helps preserve the intracellular glutathione and the ATP pool. ${ }^{166,170}$ These properties all appear useful in the proposed context of recovering from TBI. FBP appears to reduce $\mathrm{Na}+\mathrm{K}+$ ATPase activity and reduces ATP turnover. ${ }^{170}$

There is potential substrate cycling between fructose 6-phosphate (F-6P) and FBP. FBPase catalyzes the hydrolysis of FBP back to F-6P, a futile cycle, that wastes ATP and at times might help deal with excess [ATP] levels.

\section{Lithium's inhibition of PGM (Group 5)}

PGM itself is activated by glucose-1,6-biphosphate; a normal adult can produce up to $2 \mathrm{~g} / \mathrm{d}$ of galactose; ${ }^{124}$ thus, lithium (or a low cell $\left[\mathrm{Mg}^{++}\right]$) will tend to slow the conversion of the galactose product G-1-P to G-6-P, and this results in a higher level of residual galactose and its product - galactose-1P, which is both an IMPase substrate and a competitive IMPase inhibitor - and will thus tend to increase both inositol depletion and increase InsP enhancement by adding to the substrate inhibition provided by the other similar minor sugar phosphates, as a build-up of excess Ins-P1-like substrate tends to increase the net inhibition of the IMPase, which will appear to increase the "lithium sensitivity".

Most galactose in breast milk comes from blood rather than local synthesis, having galactose available before birth might help to limit damage, associated with the intrinsic "mild TBI" of birth.

There is another futile cycle between galactose-phosphorylation and dephosphorylation; the latter is performed by the IMPase. Lithium's interference with galactose metabolism suggests that $\mathrm{Li}^{+}$treatment could potentially change calorie requirements and could also alter certain protein-glycosylation patterns, which might be relevant to immune changes, eg, the thyroiditis often seen post $\mathrm{Li}^{+}$; this might provide the basis of potential future, in vitro, objective disease-state markers in mood disorders.

\section{Conformational disease, protein folding: inositol depletion, $\mathrm{Mg}^{++}$, the unfolded protein response, and autophagy (Group 2/Group X)}

$\mathrm{Mg}^{++}$is involved in protein and RNA folding. Amylin misfolding may be magnesium dose dependent in diabetic patients. ${ }^{171}$ If the depletion of cell ATP is severe, this can result in disruption of the protein synthetic structures, and if cells are deprived of oxygen or similar factors, proteins may become mis-folded. This may explain why $\mathrm{Li}^{+}$ also has effects on systems related to the UPR. This area is complex and beyond the scope of this study, the UPR is signaled through various factors, including inositol-requiring protein $1 \alpha$; within this system, $\mathrm{Li}^{+}$is again acting seemingly in this case, partly via a bulk, cytoplasmic inositol depletion mechanism, again, in competition with $\mathrm{Mg}^{++} \cdot{ }^{172}$

\section{Some clinical implications}

Adding inositol to lithium therapy has been claimed to (paradoxically) improve depression and anxiety. ${ }^{173}$ This argues against inositol depletion as the key or sole mechanism of action of $\mathrm{Li}^{+}$; however, it is consistent with the idea, which the new model readily permits, that inositol depletion and inositol phosphate enhancement (and sugar phosphate enhancement) act as cooperative, semi-independent, sub-mechanisms.

The key concept that lithium may be (particularly adapted to) acting in a low $\left[\mathrm{Mg}^{++}\right]$environment, as well as being congruent with the rationale for the proposed mechanism, removes some of the apparent paradoxes; it would require less stimulation to set up, or maintain InsP enhancement/ inositol depletion - note that InsP2 levels would also tend to increase - due to the (dual) inhibition of IPPase, due to low $\mathrm{Mg}^{++}$and the action of lithium on the IPP, and the (lesser) $\mathrm{Mg}^{++}$requirements of IPPase, low $\left[\mathrm{Mg}^{++}\right]$alone, or more so if combined with $\mathrm{Li}^{+}$, would also further restrict cAMP formation, thus helping to restore normalize cell $\left[\mathrm{Mg}^{++}\right]$ concentrations.

In cells with a low $\left[\mathrm{Mg}^{++}\right]$, as well as a greater limitation of GSK-3, lithium would have a greater effect on the IMPase; it would provide additional potential chelation buffering for both $\mathrm{Ca}^{++}$and $\mathrm{Mg}^{++}$, trap more Pi, and further limit inositol availability, and limit signaling (as originally proposed) via limiting PKC and DAG and by clamping cell $\left[\mathrm{Mg}^{++}\right]$and $\left[\mathrm{Ca}^{++}\right]$and also clamping TRPM7 channels and at times potentially limiting [Pi] and ATP levels, which mechanisms dominate would vary with the phase of the mood disorder.

The difference between "high" or "low" mood may be due in part to which "driving" receptor systems in a particular network might be on or off the levels of extracellular and intracellular $\left[\mathrm{Mg}^{++}\right]$and what state secondary systems, eg, adenosine and AMP kinase, might be in and factors such as the possible extent of $\left[\mathrm{Mg}^{++}\right]$-dependent $\mathrm{Na}+\mathrm{K}+$ ATPase inhibition, as the $\mathrm{Na}+\mathrm{K}+$ ATPase consumes $\sim 40 \%-60 \%$ of the (glycolytic) ATP in neurons, and cells become more excitable as membrane potentials drop. If depression and mania both reflect low intracellular $\left[\mathrm{Mg}^{++}\right]$states, as implied by the IMPase kinetics, lower levels of ATP appear to 
correlate with lower mood. Extracellular $\left[\mathrm{Mg}^{++}\right]$may have a role at the "upper" mood pole; extracellular $\mathrm{Mg}^{++}$, similarly to ketamine, gates glutamate receptors. ${ }^{174}$

\section{Rebound mania: a clue to the nature of the switch mechanism in mood disorders}

A corollary of this proposed method of $\mathrm{Li}^{+}$action on the IMPase is that, at least in the fast turnover state, otherwise there is little build-up of InsP, if lithium is suddenly stoppedif cell free $\left[\mathrm{Mg}^{++}\right]$levels rapidly rise, there may be a potential for a rapid release of cell $\mathrm{Mg}^{++}$and inositol, following lysis of the InsP1/2, etc. (also with potential for osmotic effects) and a potential to disrupt the cytoskeleton. Cell $\left[\mathrm{Ca}^{++}\right]$levels would also tend to rise.

An increase in the IMPase numbers would permit a more rapid rebound, with a greater risk of excess $\mathrm{Mg}^{++}$export to the extracellular compartment.

There would be more $\mathrm{Pi}$, available from the lysis of InsP1/P2, etc., somewhat more $\mathrm{pH}$ buffering, the increased [Pi], phosphate could affect metabolic regulation via altered protein phosphorylation/de-phosphorylation ratios, and more [Pi] would be available to potentially form more ATP. Sudden cessation of lithium is often associated with rebound mania; this provides a model for the "chemical state" in mania, the extra cell $\left[\mathrm{Mg}^{++}\right]$might re-activate other $\mathrm{Mg}^{++}$-dependent enzymes and re-activate the GSK-3, switch off that part of the now, no longer required, protective system.

Increasing dietary $\mathrm{Mg}$ (assuming that there are no membrane transport problems) should tend to improve mood, reduce suicide risks, improve the response rate, and maintain stability and resilience. When lithium augmentation is used, it predicts that $\mathrm{Mg}^{++}$should tend to replace, or further augment antidepressants, even during lithium augmentation (more so, when IMPase numbers are increased). There are numerous variables, $\mathrm{Mg} / \mathrm{Mg}^{++}$levels (both intra- and extracellular), [ATP-Mg] levels, $\mathrm{Ca}^{++}$, ATP/ADP/AMP, AMPK, CreatineP, Pi, PPi, NAD+, adenosine levels/ratios, IMPase numbers, turnover rate, $\mathrm{pH}$, polyamines, the levels of various other buffering systems, redox states, mitochondrial competence, PPP activity, GSH, Na+/K+ ATPase inhibitory activity, osmotic factors, etc.

In some conditions, quite small levels of lithium, perhaps only as little as $0.2 \mathrm{mmol} / \mathrm{L}$, appear to begin to be somewhat effective in prophylaxis and in augmenting mood, alongside antidepressants; yet more $\mathrm{Li}^{+}$seems required to subdue elevated mood, suggesting perhaps a lower cell [ATP] level in depression than in mania, as ATP itself chelates $\mathrm{Mg}^{++}$more at higher [ATP] levels, ${ }^{7}$ perhaps in mania, there is a potentially somewhat higher cell ATP, the IMPase activity is relatively a bit more constrained - as $\mathrm{Mg}^{++}$is less available - as it is bound by the extra ATP, but perhaps IMPase numbers may be somewhat increased.

At the lower end of the $\left[\mathrm{Mg}^{++}\right]$concentration range, the kinetics ${ }^{53}$ suggests a potentially several-fold greater increase in IMPase inhibition, compared to lithium acting in a cell with a normal $\left[\mathrm{Mg}^{++}\right]$. Possibly unusual conditions of a raised cell $[\mathrm{ATP}]$ might sometimes result in a relatively lowered cell $\left[\mathrm{Mg}^{++}\right]$. Mismatched $\mathrm{Mg}^{++} / \mathrm{ATP}$, and/or mismatched intracellular versus extracellular $\left[\mathrm{Mg}^{++}\right]$levels might explain "mixed" mood states. A higher cell $\left[\mathrm{Mg}^{++}\right]$may do little useful to cell energetics, if [ATP] itself is relatively low.

\section{A three-way relationship, turnover, IMPase numbers, the activation point of a critical cell $\left[\mathrm{Mg}^{++}\right]$concentration}

Increased IMPase numbers disrupt this system, so that it would become less sensitive to sub-optimal $\left[\mathrm{Mg}^{++}\right]$concentrations, and it is not necessarily always a matter of cell $\left[\mathrm{Mg}^{++}\right]$concentrations. Rather, the stability of the cell protection system would rely on the correct balance between the $\left[\mathrm{Mg}^{++}\right] /[\mathrm{Mg}-\mathrm{ATP}]$, the IMPase numbers, and the system turnover rate. For a given turnover rate, the IMPase numbers would help modulate the set-point of the proposed cell protection system: the regulation of IMPase copy numbers, involving the prolyl oligopeptidase,$^{54}$ appears fundamental to the stability of a core component of the system.

A low cell $\left[\mathrm{Mg}^{++}\right]$itself would not need to equate directly to low mood, as $\mathrm{Li}^{+}$, which can displace $\mathrm{Mg}^{++}$from some, but not all cellular sites, does not seem to lower normal mood, possibly a higher cell $\left[\mathrm{ATP}-\mathrm{Mg}^{++}\right.$] (tending to be bound to ATP, and thus tending, presumably, to be limited by $\mathrm{Mg}$ ATP binding, perhaps potentially InsP-Mg-ATP binding) might equate to a more energetic state, perhaps equating to higher mood.

High levels of cell [ATP] can activate certain $\mathrm{K}+$ ion channels, which can cause membrane depolarization and increase cell excitability. Depleting cell [Pi] tends to limit the formation of ATP. ${ }^{124}$

Notwithstanding the dose of $\mathrm{Li}^{+}$used, the degree of cell protection provided by lithium may vary. The proposed action of lithium is to bolster the intrinsic cell protection system, triggered by a low cell $\left[\mathrm{Mg}^{++}\right]$, reflecting conditions of altered or low-(brain) cell [ATP].

Some modest degree of GSK-3-mediated background protective action occurs in normal cell $\left[\mathrm{Mg}^{++}\right]$. IMPase, IPPase, and GSK-3 are further inhibited in conditions of 
lowered cell $\left[\mathrm{Mg}^{++}\right]$and/or by $\mathrm{Li}^{+}$, further increasing the available level of protection. Lithium requires an adequately fast turnover, to generate a significant InsP enhancement/ inositol depletion; a low cell $\left[\mathrm{Mg}^{++}\right]$alone may not be enough to produce a full effect - if turnover is slow - this might explain why adding an antidepressant to $\mathrm{Li}^{+}$in depression is often required.

Maximum protection requires reasonably fast turnover, and it is suggested also increased local levels of other (PPPderived) sugar phosphates, perhaps particularly galactose-P.

The model contains informative constraints on the way the system appears to function, providing clues about the metabolic conditions that may prevail. It is likely that lithium responsive conditions reflect disorders in which there are likely to occur significant phases of a lower (neuronal) cell $\left[\mathrm{Mg}^{++}\right]$- although $\mathrm{Li}^{+}$would still offer some protection even with a normal cell $\left[\mathrm{Mg}^{++}\right]$. The fate of cell $\mathrm{Mg}^{++}$may be coupled to a certain extent to the fate of cell ATP.

\section{Altered IMPase numbers, metabolic disorder risks and cell $\left[\mathrm{Mg}^{++}\right]$regulation}

The IMPase enzyme is well conserved across species; the proposed mood-buffering mechanism has limits. It can be destabilized particularly by epigenetic changes in IMPase numbers, ${ }^{54}$ and it is suggested by low dietary $\mathrm{Mg}$ intake or other factors reducing cell $\left[\mathrm{Mg}^{++}\right]$. A "compensated system", ie, normal IMPase numbers, and lower mean cell $\left[\mathrm{Mg}^{++}\right]$might imply a restricted range of affect. Even small amounts of Ins-phosphates might be sufficient to buffer the much lower $\mathrm{Ca}^{++}$concentrations. It is possible to conceive of cells having increased IMPase numbers; having a potentially higher turnover rate, with little inositol depletion/InsP enhancement; - perhaps associated with greater post-synaptic stimulation perhaps a higher mood. Increasing the IMPase numbers above the normal optimum levels - as well as reducing lithium sensitivity - would desensitize a part of the cell " $\left[\mathrm{Mg}^{++}\right]$concentration management system", alter the system's threshold, and cause it to lag in responding to lower cell $\left[\mathrm{Mg}^{++}\right]$levels, so that cell protection would not be fully activated until $\left[\mathrm{Mg}^{++}\right]$concentrations reached lower than usual levels, ie, an increase in IMPase numbers would tend to reduce the level of protection provided by the system, undermine the metabolic precision, reduce the amount of membrane and non-membrane $\mathrm{Mg}^{++}$-binding capacity available, and free up Pi to potentially form more ATP.

It suggests that (brain) cells may, to a considerable degree, be routinely reasonably well protected against the effects of conditions associated with a low cell $\left[\mathrm{Mg}^{++}\right]$level, unless
IMPase numbers are increased too much, an increased turnover rate ("racing thoughts?") might help compensate for an increase in IMPase numbers, activation of the system would tend to "clamp" mood (but then also subtly restricting the range of affect).

With the system is working normally, IMPase normal and IMPase numbers not increased too excessively, cells would then be reasonably well protected against reduced $\left[\mathrm{Mg}^{++}\right]$ levels: making the actual cell $\left[\mathrm{Mg}^{++}\right]$concentration, relatively non-critical, if and turnover rate is not too slow, not blunting the precision of metabolic fine control. If IMPase numbers are increased, at some point a low intracellular $\left[\mathrm{Mg}^{++}\right]$level no longer provides sufficient $\mathrm{Li}^{+}$-like (mood) stabilization, there is insufficient InsP enhancement/inositol depletion, as too much substrate would leak past the increased IMPase enzyme activity and the intrinsic lithium-like mood stabilization becomes impaired.

Optimum function and stability are likely to occur within a normal range of cell $\left[\mathrm{Mg}^{++}\right]$, normal $[\mathrm{Mg}-\mathrm{ATP}]$, and normal IMPase numbers. "Compensated" function would occur with the InsP buffering system operational, in cells with both a low $\left[\mathrm{Mg}^{++}\right]$, increased IMPase numbers, and a de-sensitized, relatively inactivated cell $\left[\mathrm{Mg}^{++}\right]$concentration management system, the potential for instability and "un-moderated" metabolic damage would seem greater; this may partly explain why "metabolic disorder risks" appear more "bloated" alongside the more common psychiatric disorders.

The expanded, "inositol depletion-Ins phosphate enhancement" model that emerges suggests that the inhibition by lithium (and/or a low $\mathrm{Mg}^{++}$level) of the IMPase, and related systems, is not at all wasteful and appears to make use of "everything"; both the inositol phosphate enhancement and the complimentary inositol depletion mechanisms, in the process potentially creating additional $\mathrm{Mg}^{++} / \mathrm{Ca}^{++}$and metal binding capacity (and consequently additional anti-oxidant activity), increased GSK-3 inhibition, perhaps in certain phases of FBPase and BPNase inhibition, the inhibition of $\mathrm{Mg}^{++} / \mathrm{Ca}^{++}$channel opening, effects via UPR/autophagy, and indeed possibly the consequent intracellular Pi depletion and inhibition of minor sugar de-phosphorylations (including galactose-P), with alterations of $\mathrm{Mg}^{++}$-dependent G-protein coupling, reduced cAMP formation, shifts in phosphorylation patterns, the activation of PRPP formation, with complex downstream effects, etc.

The magnesium-dependent kinetics of the IMPase, IPPase, GSK-3, etc., the $\mathrm{Mg}^{++} / \mathrm{Ca}^{++}$chelating, buffering properties of the inositol-phosphate part of the pathway, the inositol-PIP2 dependence of TRMP7 $\mathrm{Mg}^{++} / \mathrm{Ca}^{++}$channels, 
all suggest that lithium's fundamental action is to protect cells in the context of marshaling protection from head injury using a variety of methods arrayed against the effects associated with a low cell $\left[\mathrm{Mg}^{++}\right]$(including actions that potentially eventually help to tend to normalize cell $\left[\mathrm{Mg}^{++}\right]$ levels) and that lithium achieves this, as it neatly mimics a lowered cell $\left[\mathrm{Mg}^{++}\right]$.

It suggests that the regulation of intracellular $\left[\mathrm{Mg}^{++}\right]$ (loosely linked to Pi, NAD+, and ATP) and the regulation of IMPase numbers are fundamental to the regulation of mood.

The proposed expanded inositol depletion enhancement mechanism kinetics reveal it to be a mechanism that is directly and critically regulated by $\mathrm{Mg}^{++}$, closely linked to factors influencing intracellular $\left[\mathrm{Mg}^{++}\right]$and $\left[\mathrm{Ca}^{++}\right]$concentrations. An outline, overlapping pathway for the action of valproate, including via a NAD/purine/ATP/5HT-conserving mechanism, is proposed.

If a complex set of head injury, TBI, related, latent failsafe systems for managing lowered cell $\left[\mathrm{Mg}^{++}\right]$does exist, this may have masked the true potential scale and nature of effects on cells of a sub-optimal, cell $\left[\mathrm{Mg}^{++}\right]$, and may have obscured the potential pathological consequences of (uncompensated) cell $\mathrm{Mg}^{++}$deficiency/dys-regulation. This potential "IMPase number", "masking effect", might provide one possible reason why it has not perhaps been easy to unpick an unambiguous role for magnesium in these disorders.

The proposal suggests that intracellular $\left[\mathrm{Mg}^{++}\right]$enjoys a privileged role, so that relative intracellular $\left[\mathrm{Mg}^{++}\right]$deficiency and cell $\left[\mathrm{Mg}^{++}\right]$levels might not be all that critical (or informative), unless IMPase numbers are also disrupted. It implies that a fair stability of mood buffering may prevail as long as IMPase numbers are satisfactory, but that once IMPase numbers become increased beyond a certain point, effects on mood become more likely.

If InsP, or similar sugar phosphates, forms part a $\mathrm{Mg}^{++}$ buffering system, it couples these mechanisms to ATP, a major cell $\mathrm{Mg}^{++}$buffer. As ATP is one of the main buffers for $\mathrm{Mg}^{++}$, any sudden or major change in ATP production may be associated with a change in $\left[\mathrm{Mg}^{++}\right]$level and a change in requirements for $\mathrm{Mg}^{++}$buffering, as this has to match the $\left[\mathrm{Mg}^{++}\right]$level to optimize energetic-phosphor group transfer efficiency, prompting a need for specific arrangements to link cell-signaling to cell-energetics, and at times, actively buffer $\mathrm{Pi}$ and $\mathrm{Mg}^{++}$.

The evidence of mitochondrial, glycolytic disturbances in bipolar suggests that cell energy disturbances will inevitably involve $\left[\mathrm{ATP}-\mathrm{Mg}^{++}\right]$and similar factors, including ATP breakdown products, eg, inosine acting on BDNFrelated systems. ${ }^{128}$
It is possible that InsP/sugar phosphates interacting with the Mg bound to ATP (also linked to AMPkinase), affecting the efficiency of phosphate group energetic transfer, and like the two identified futile ATP cycles, may be relevant to weight gain. Various "minor sugar phosphates" would appear to represent components of the system that would not require strong receptor drive, or fast turnover, to maintain. Excess IMPase numbers may critically undermine mechanisms for innate resilience and unmask potential metabolic effects, consequent upon "unprotected" low cell $\left[\mathrm{Mg}^{++}\right]$.

Pre/post-treatment with $\mathrm{Li}^{+}$and/or galactose might improve outcome in TBI or perinatal head injury. Administering extra $\mathrm{Mg}$ might improve response to antidepressants, valproate, $\mathrm{CBZ}$, and/or $\mathrm{Li}^{+}$augmentation. Galactose (perhaps in the form of milk) should tend to help augment $\mathrm{Li}^{+}$augmentation. $\mathrm{Mg}^{++}$itself has a statin-like cholesterol-lowering effects. ${ }^{175}$ Raised cholesterol might sometimes be a potential indicator for a lack of systemic magnesium. Inadvertently activating aspects of the postulated "low $\left[\mathrm{Mg}^{++}\right]$cell protection mechanisms" might afford unwitting tumor resistance during cancer therapy or metastasis.

\section{On the nature of "bipolar" disorder, the enigmatic variations}

Beyond the interesting implication that mood disorders may occur in cells with an altered $\left[\mathrm{Mg}^{++}\right]$environment, what else might this new model tell us about the pathology of mood disorders, and its implications for schizophrenia? The model begins help map out the relevant mechanisms. Symptoms occur when key regulatory mechanisms, including the regulation of IMPase numbers, break down.

Bipolar disorder may reflect the behavior of a disregulated mood regulating system, perhaps dis-regulated both at the level of mood and at the level of systemic metabolic effects. A core feature of mood disorders is an alteration of the systemic energy level; this should be reflected in disturbances of cell [ATP] and with factors closely related to ATP.

Given the broad range of protection apparently provided by $\mathrm{Li}^{+}$in mood disorders, the apparent lack of sensitivity to $\mathrm{Li}^{+}$in the schizophrenia(s) provides an important paradox, suggesting that there is less obviously an issue of an apparent "low cell $\left[\mathrm{Mg}^{++}\right]$" phase contributing to the pathology of the schizophrenia - unless this relates to some altered or excess numbers of IMPase enzymes. The same key factors that operate in bipolar to influence $\left[\mathrm{Mg}^{++}\right]$may also operate in schizophrenia. There is the parsimonious possibility that both disorders share a similar chemistry - differences could arise from a relative inability of lithium non-responsive systems 
to set up an effective, full proposed enhancement/depletion, $\mathrm{Mg}^{++} / \mathrm{Ca}^{++}$buffering system. This might force the adoption of an inferior, perhaps possibly polyamine-based cellular defense system; this may yield more motley symptoms, perhaps further complicated by further small mutations, whose effects might otherwise be masked and also expose a greater potential susceptibility to perinatal damage.

\section{Conclusion: the "how" and the "why" of lithium action}

The new model suggests that lithium therapy is pre-configured to be able to utilize cellular fail-safe mechanisms, enabling survival in pathological conditions, associated with the depletion of cell $\left[\mathrm{Mg}^{++}\right]$; it is proposed that compensatory cell protection becomes increasingly required as neuronal cell $\left[\mathrm{Mg}^{++}\right]$concentrations decline.

As $\mathrm{Li}^{+}$acts via competition with $\mathrm{Mg}^{++}$, so that $\mathrm{Li}^{+}$mimics a lowered intracellular $\left[\mathrm{Mg}^{++}\right]$, cell protection mechanisms are thus also further activated as $\left[\mathrm{Li}^{+}\right]$concentrations rise.

Inositol depletion and inositol phosphate enhancement represent separate sub-components of a proposed low cell $\left[\mathrm{Mg}^{++}\right]$cell protection system, including GSK-3, enabling survival in conditions associated with a dangerously low cell $\left[\mathrm{Mg}^{++}\right]$.

Cell protection is required alongside the depletion of cell $\left[\mathrm{Mg}^{++}\right]$, a fundamental response to TBI, during which, despite a co-existing depletion of cell $\left[\right.$ ATP] (brain) cell $\left[\mathrm{Mg}^{++}\right]$, plummets to a critically low level.

These systems appear pre-configured to optimize neuroprotection post TBI; following which, the brain cell $\left[\mathrm{Mg}^{++}\right]$ paradoxically drops to a critically low level.

The fail-safe model postulates the existence of a set of pre-programmed biochemical responses - "special measures" adapted to provide protection against mechanical trauma, brain injury, involving the activation of pathways sensitive to a low cell free $\left[\mathrm{Mg}^{++}\right]$that appear to be "parasitically" utilized by lithium to generate its therapeutic effects.

These systems would also provide background protection and resilience to cells generally; this may also be relevant to cell survival in cancer and perhaps other states of altered cell [ATP]. The model suggests that novel metabolic situations, including conditions of low cell $\left[\mathrm{Mg}^{++}\right]$, may arise. The model demonstrates compatibility with conventional mono-aminelinked systems and with the action of other mood stabilizers, leaving much detail to resolve.

The proposed low cell $\left[\mathrm{Mg}^{++}\right]$, fail-safe cell protection system helps to diffuse the paradoxes, contradictions, and limitations of the original inositol depletion model. Lithium's actions, rather than being some happy coincidence, can now be better understood as reflecting actions on a set of low cell $\left[\mathrm{Mg}^{++}\right]$, TBI, mechanical shock, and integrin-related cellsurvival mechanisms.

When considering how lithium works, we should consider the effects of what happens when cell $\left[\mathrm{Mg}^{++}\right]$levels shift, which is comparable to what happens when $\mathrm{Li}^{+}$is added, the situation, par-excellence when cell $\left[\mathrm{Mg}^{++}\right]$levels severely drop, eg, post TBI.

In examining the consequences of the accretion of inositol phosphate (and/or) other PPP, including glutathione metabolism-related, sugar phosphate-type substrates, it represents a comprehensive, more understandable model related to damage limitation. The characteristics and kinetics of the IMPase, IPPase, and GSK-3 enzymes match the proposed model perfectly.

The central concept is that the therapeutic effects of lithium occur indirectly via activating a cascade of preexisting, failsafe pathways, configured to activate - in an evolutionary context - against "unavoidable", perinatal head injury insults, as (brain) cell free $\left[\mathrm{Mg}^{++}\right]$drops; these are also activated by $\mathrm{Li}^{+}$, as lithium mimics a lowered intracellular free $\left[\mathrm{Mg}^{++}\right]$level.

These pathways appear to act by multi-leveled, multifaceted sub-mechanisms; it is proposed including the buffering limiting of cell $\mathrm{Mg}^{++}$and cell $\mathrm{Ca}^{++}$, and at times by appearing to limit [Pi], and thus, at certain times, potentially limiting ATP formation. Lithium would only become required if the system is perturbed beyond its normal working limits; the system would still operate in the absence of $\mathrm{Li}^{+}$.

Adding $\mathrm{Li}^{+}$enhances the resilience and boosts the degree of protection that the proposed innate mood-stabilizing system can provide. The enzyme kinetics suggests that if turnover is rapid, with normal IMPase numbers, low cell $\left[\mathrm{Mg}^{++}\right]$levels can potentially drive inositol depletion and InsPhosphate enhancement, particularly, if there are additional IMPase (co)-substrates present.

The function of the proposed system is to enable the cell to survive metabolic crisis conditions associated with an altered, particularly a significantly lowered, cell $\left[\mathrm{Mg}^{++}\right]$.

Lithium treatment would reinforce preexisting low cell $\left[\mathrm{Mg}^{++}\right]$, and TBI-related mechanisms, permitting highly physiological responses, further explaining the lack of effect of $\mathrm{Li}^{+}$in normal individuals and its often remarkable specificity and potency.

The proposed mechanism explains both how and why lithium works and why it can work so well. The proposed fail-safe mechanisms provide a set of preexisting pathways for low cell $\left[\mathrm{Mg}^{++}\right]$and for $\mathrm{Li}^{+}$action. Excess IMPase numbers may undermine parts of the mechanism determining the innate resilience to mood disorders. 
The existence of pre-programmed adaptive responses to conditions associated with a low intracellular free $\left[\mathrm{Mg}^{++}\right]$ may have masked the impact of the lack of systemic $\mathrm{Mg}^{++}$; this may help explain why various forms of metabolic disorders appear more prevalent alongside the more common psychiatric disorders.

The model permits a better understanding of links between cell energetics, mono-amine systems, and mechanisms underpinning cell resilience and mood stabilization.

Derived from a different premise, yet still based on the same kinetics, and the $\left[\mathrm{Mg}^{++}\right]$dependency of this family of enzymes, the fail-safe concept spontaneously "transmogrifies" into a much expanded, inositol depletion-inositol phosphate enhancement-GSK-3 model, furnishing details that appear AWOL from earlier concepts.

An informative extension to both the inositol depletion and the GSK-3 models emerges, providing a new context, unifying and expanding existing concepts. The new model provides insights into the configuration of an unexpectedly subtle system, underpinning cellular aspects of mood. Further biochemical details will be addressed in a future paper.

\section{Acknowledgments}

For S.G., with particular thanks to Dr Rem van Woerkom for assistance with the references and to Prof Sir M Berridge FRS for helpful comments, particularly to early issues of neuronal Ins concentrations, Prof F Oyebodi for general discussion, and those at Birmingham \& Solihull Mental Health Foundation Trust, T Green, and Dr Alan Bradley Sparkes. In memory of Dr D.H.M Woollam FRS and Prof Sir Martin Roth FRS. This research received no specific grant from any funding agency in the public, commercial, or not-for-profit sectors.

\section{Disclosure}

The author reports no conflicts of interest in this work.

\section{References}

1. Berridge MJ, Irvine RF. Inositol phosphates and cell signaling. Nature. 1989;41:197-205.

2. Berridge MJ, Downes CP, Hanley MR. Lithium amplifies agonistdependent phosphatidylinositol responses in brain and salivary glands. Biochem J. 1982;206:587-595.

3. Berridge MJ, Downes CP, Hanley MR. Neural and developmental action of lithium; a unifying hypothesis. Cell. 1989;59:411-419.

4. Hallcher LM, Sherman WR. The effects of lithium ion and other agents on the activity of myo-inositol-1-phosphatase from bovine brain. $J$ Biol Chem. 1980;255:10896-10901.

5. Klein PS, Melton DA. A molecular mechanism for the effect of lithium on development. Proc Natl Acad Sci U S A. 1996;93:8455-8459.

6. Ryves WJ, Harwood AJ. Lithium inhibits glycogen synthase kinase-3 by completion for magnesium. Biochem Biophys Res Com. 2001; 280(3):720-725.
7. Struewing IT, Barnet CD, Tang T, Mao CD. Lithium increases PGCa expression and mitochondrial biogenesis in primary bovine cortex aortic endothelial cells. FEBS J. 2007;274(11):2749-2765.

8. Brown KM, Tracy DK. Lithium; the pharmacodynamics of the amazing ion. Ther Adv Psychopharmacol. 2013;3(3):163-176.

9. Birch NJ. Lithium and magnesium-dependent enzymes. Lancet. 1974; 2(7886):965-966.

10. Di Daniel E, Cheng L, Maycox PR, Mudge AW. The common inositol reversible effect of mood stabilizers on neurons does not involve GSK-3 inhibition, myo-inositol-1-phosphate synthase or the sodiumdependent myo-inositol transporters. Mol Cell Neurosci. 2006;32(1-2): $27-36$.

11. Harwood AJ. Lithium and Bipolar mood disorder; the inositol-depletion hypothesis revisited. Mol Psychiatry. 2005;10:117-126.

12. Pasquali L, Busceti CL, Fulceri F, Paparelli A, Fornai F. Intracellular pathways underlying the effects of lithium. Behav Pharmacol. 2010; 21(5-6):473-492.

13. Diniz BS, Machado-Vieira R, Forlenza OV. Lithium and neuroprotection, translational evidence and implications for the treatment of neuropsychiatric disorders. Neuropsychiatr Dis treat. 2013;9:493-500.

14. Chiu CT, Chuang DM. Molecular actions and therapeutic potential of lithium in preclinical and clinical studies of CNS disorders. Pharmacol Ther. 2010;128(2):281-304.

15. Machado-Vieira R, Manji HK, Zarate CA. The role of Lithium in the treatment of Bipolar disorder: convergent evidence for neurotrophic effects as a unifying hypothesis. Bipolar Disord. 2009;11(suppl 2): 92-109.

16. Lenox RH, Hahn CG. Overview of the mechanism of action of Lithium in the brain: fifty-year update. J Clin Psychiatry. 2000; 61(supp1 9):5-15.

17. Layden B, Diven C, Minadeo N, Bryant FB, Mota de Freitas D. $\mathrm{Li}+\mathrm{Mg} 2$ competition at therapeutic intracellular Li+ levels in human neuroblastoma SH-SY5Y cells. Bipolar Disord. 2000;2(3 pt 1): 200-204.

18. Amari L, Layden B, Nikolakopoulos J, et al. Li+ displaces $\mathrm{Mg}^{++}$from binding sites within the nerve cell. Ann Biochem. 1999;272:1-7.

19. Birch NJ, Jenner FA. Distribution of lithium and its effects on the distribution of other Ions in the rat. Br J Pharm. 1973;47: 586-594.

20. Golshani-Hebroni S. $\mathrm{Mg}^{++}$requirements for MtHK binding and $\mathrm{Mg}^{++}$ stabilization of mitochondrial membranes via activation of MtHK \& MtCK and promotion of mitochondrial permeability pore closure: a hypothesis on mechanisms underlying $\mathrm{Mg}^{++}$'s antioxidant and cytoprotective effects. Gene. 2016;581(1):1-13.

21. York JD, Ponder JW, Majerus PW. Definition of a metal dependent/ $\mathrm{Li}+-$ inhibited phosphomonoesterase protein family based upon a conserved three dimensional core structure. Proc Natl Acad Sci U S A. 1995;92:5149-5152.

22. Masuda CA, Xavier MA, Mattos KA, Galina A, Montero-Lomeli M. Phosphoglucomutase is an in vivo lithium target in yeast. J Biol Chem. 2001;276:37794-37801.

23. Brown DA, Cook RA. Role of metal cofactors in enzyme regulation. Differences in the regulatory properties of the Escherichia Coli nicotamine adenine dinucleotide phosphate specific malic enzyme, depending on whether magnesium ion or manganese ion serves as divalent cation. Biochemistry. 1981;20(9):2503-2512.

24. Heaton FW. Magnesium requirement for enzymes and hormones. Biochem Soc Trans. 1973;1:67-70.

25. Romani AMP, Scarpa A. Regulation of cellular magnesium. Front Biosci. 2000;5:720-734.

26. Romani AMP. Intracellular magnesium homeostasis. Arch Biochem Biophys. 2011;512(1):1-23.

27. Corkey BE, Duszynski J, Rich TL, Matschinsky B, Williamson JRJ. Regulation of free and bound cell magnesium in rat hepatocytes and isolated mitochondria. Biol Chem. 1986;261:2567-2574.

28. Wacker WEC. The biochemistry of magnesium. Ann N Y Acad Sci. 1969;162(2):717-726. 
29. George GA, Heaton FW. Effect of magnesium deficiency on energy metabolism and protein synthesis by liver. Int J Biochem. 1978;9:421-425.

30. Bottomley PA, Hardy CJ. Rapid, reliable in vivo assays of phosphate metabolites by nuclear magnetic resonance. Clin Chem. 1989;35: 392-395.

31. Fawcett WJ, Haxby EJ, Male DA. Magnesium physiology and pharmacology. Br J Anaesth. 1999;83(2):302-320.

32. Langley WF, Mann D. Central nervous system magnesium deficiency. Arch Intern Med. 1991;151(3):593-596.

33. Vink R, McIntosh TK, Demendiuk P, et al. Decline in intracellular free magnesium concentration is associated with irreversible tissue injury following brain trauma. J Biol Chem. 1988;263:757-761.

34. Vink R, Cook NL, van den Heuvel C. Magnesium in acute and chronic brain injury: an update. Magnes Res. 2009;22(3):158S-162S.

35. Sen AP, Gulati A. Use of magnesium in traumatic brain injury. Neurotherapeutics. 2010;7:91-99.

36. Beaulieu J-M, Marion S, Rodriguez RM, et al. A beta arrestin 2 signaling complex mediates lithium action on behavior. Cell. 2008;132: 125-136.

37. Zea R, Cami-Ulal G, Pohl NL. Thermodynamics of binding of divalent magnesium and manganese to uridine phosphates: implications for diabetes-related hypomagnesaemia and carbohydrate biocatalysis. Chem Cent J. 2008;2:15.

38. Gunther T. Concentration, compartmentation and metabolic function of intracellular free Mg2+. Magnes Res. 2006;19(4):225-236.

39. Grubbs RD, Maguire ME. Magnesium as a regulatory cation: criteria and evaluation. Magnesium. 1987;6(3):113-127.

40. Murphy E. Mysteries of magnesium homeostasis. Circ Res. 2000;86: 245-248.

41. Grubbs RD. Intracellular magnesium and magnesium buffering. Biometals. 2002;15(3):251-259.

42. Dudev T, Lim C. Competition between $\mathrm{Li}+$ and $\mathrm{Mg} 2+$ in metalloproteins. Implications for lithium therapy. $J$ Am Chem Soc. 2011;133: 9506-9515.

43. Goldberg H, Clayman P, Skorecki K. Mechanism of Li inhibition of vasopressin - sensitive adenylate cyclase in cultured renal epithelial cells. Am J Physiol. 1988;255:F995-F1002.

44. Belmaker RH, Bersudsky Y, Agam G, Levine J, Kofman O. How does lithium work on manic depression? Clinical and psychological correlates of the inositol theory. Аnпи Rev Med. 1996;47:47-56.

45. Cech SY, Maguire ME. Magnesium regulation of the beta-receptoradenylate cyclase complex, 1 . Effects of manganese on receptor binding and cyclase activation. Mol Pharmacol. 1982;22:267-272.

46. Maguire ME. Magnesium regulation of the beta-receptor-adenylate cyclase complex, II $\mathrm{Sc}^{++}+$as a $\mathrm{Mg}^{++}$antagonist. Mol Pharmacol. 1982;22:274-280.

47. Avissar S, Murphy DL, Schreiber G. Magnesium reversal of Lithium inhibition of beta-adrenergic and muscarinic receptor coupling to G Proteins. Biochem Pharmacol. 1991;41:171-175.

48. Hokin LE, Dixon JF, Los GV. Acute inhibition but chronic up-regulation and stabilization of glutamate uptake in synaptosomes by Lithium. In: Manji HK, et al., editors. Bipolar Medications Mechanism of Action. Washington, DC: American Psychiatric Association; 2000:65-85.

49. Agranoff BW, Fisher SK. Inositol and the brain. Psychopharm Bull. 2001;35(3):5-18.

50. Atack JR. Lithium phosphatidylinositol signaling and bipolar disorder, role of inositol monophosphatase. In: Manji HK, et al., editors. Bipolar Medications Mechanism of Action. Washington, DC: American Psychiatric Association; 2000:1-30.

51. Lutrell BM. Cellular actions of inositol phosphates and other natural calcium and magnesium chelators. Cell Signal. 1994;6(4):355-362.

52. Lutrell BM. The biological relevance of the binding of calcium ions by inositol phosphates. J Biol Chem. 1993;268(3):1521-1524.

53. Gore MG, Greasley P, McAllister G, Ragan CI. Mammalian inositol monophosphatase: the identification of residues important for the binding of $\mathrm{Mg} 2+$ and $\mathrm{Li}+$ ions using fluorescence spectroscopy and site-directed mutagenesis. Biochem J. 1993;296:811-815.
54. Harwood AJ. Prolyl oligopeptidase, inositol phosphate signaling and lithium sensitivity. CNS Neurol Disorders Drug Targets. 2011;10(3): 333-339.

55. Inhorn RC, Majerus PW. Inositol polyphosphate-1 phosphatase from calf brain. J Biol Chem. 1987;262:15946-15952.

56. Altura BM, Gebrewold A, Altura BT, Brautbar N. Magnesium depletion impairs myocardial carbohydrate and lipid metabolism and cardiac bioenergietics and raises myocardial calcium content invivo: relationship to etiology of cardiac diseases. Bioch Mol Biol Int. 1996;40(6):1183-1190.

57. Goodwin FK, Jamison KR. In: Manic Depressive Illness, Neurobiology. (Chap. 14). Oxford: Oxford University Press; 2007:463-607.

58. McGilvery RW. Oxidative phosphorylation. Biochemistry a Functional Approach. (Chap. 10). WB Saunders Co.: Philadelphia;1970:202.

59. Bhat PJ. Galactose-1-Phosphate is a regulator of inositol monophosphatase: a fact or fiction? Med Hypotheses. 2003;60(1):123-128.

60. Ozbek PO, Dietrich AM, Duncan SE, Lee YW. Role of lipid oxidation, chelating agents and antioxidants in metallic flavour development in the oral cavity. J Agri Food Chem. 2012;60(9):2274-2280.

61. Mark RJ, Ashford JW, Goodman Y. Anticonvulsants attenuate amyloid beta-peptide neurotoxicity, $\mathrm{Ca} 2+$ deregulation and cytoskeletal pathology. Neurobiol Aging. 1995;16:187-195.

62. Wreggett KA. Inositol monophosphatase is a highly conserved enzyme having localized structural similarity to both glycerol-3phosphate dehydrogenase and heamoglobin. Biochem J. 1992;286: $147-152$.

63. Zhang YP, Liang JY, Lipscomb WN. Structural similarities between Fructose-1,6-bisphosphatase and inositol monophosphatase. Biochem Biophys Res Com. 1993;190:1080-1083.

64. Csutora P, Strasz A, Boldizisar F, et al. Inhibition of phosphoglucomutase activity by lithium alters cellular calcium homeostasis and signalling in Saccharomyces cerevisiae. Am J Physiol Cell Physiol. 2005;289(1):C58-C67.

65. Gee NS, Ragan CI, Watling KJ, et al. The purification and properties of myo-inositol monophosphatase from bovine brain. Biochem J. 1988; 249(3):883-889.

66. Silverstone PH, Hanstock CC, Fabian J, Staab R, Allen PS. Chronic Lithium does not alter human myo-inositol or phosphomonoester concentrations as measured by $1 \mathrm{H}$ and 31P MRS. Biol Psychiatry. 1996; 40:235-246.

67. Shimon H, Agam G, Belmaker RH, Hyde TM, Kleinman JE. Reduced frontal cortex inositol levels in post mortem brain of suicide victims and patients with bipolar disorder. Am J Psychiatry. 1997;154(8): $1148-1150$.

68. Eby GA, Eby KJL. Magnesium for treatment-resistant depression: a review and hypothesis. Med Hypotheses. 2010;74(4):649-660.

69. Eby GA, Eby KL. Rapid recovery from major depression using magnesium treatment. Med Hypotheses. 2006;67:362-370.

70. Robinet L. Suicides, tuberculose, senilite et terrains magnesiens [Suicides, tuberculosis, senilitis and magnesia] Bull Acad Med Paris. 1934;111:415. French

71. Banki CM, Voynik M, Papp Z, Balla KZ, Arato M. Cerebrospinal fluid magnesium and calcium related to amine metabolites, diagnosis and suicide attempts. Biol Psychiatry. 1985;20(2):163-171.

72. Tondo L, Jamison KR, Baldessarini RJ. Effects of lithium maintenance on suicidal behaviour in major mood disorders. Ann N Y Acad Sci. 1977; 836:339-351.

73. Aherns B, Miller-Oerlinghausen B, Schou M, et al. Excess cardiovascular and suicide mortality of affective disorders may be reduced by lithium prophylaxis. $J$ Affect Disord. 1995;33:67-75.

74. Chouinard G, Beauclair L, Geiser R, Etienne P. A pilot study of magnesium aspartate hydrochloride (magnesiocard) as a mood stabilizer for rapid cycling bipolar affective disorder patients. Prog Neuropsychopharmacol Biol Psychiatry. 1990;14(2):171-180.

75. Heiden A, Frey R, Presslich O, Blasbichler T, Smetana R, Kasper S. Treatment of severe mania with intravenous Magnesium as a supplementary therapy. Psychiatry Res. 1999;89:239-246. 
76. Grimaldi BL. The central role of magnesium deficiency in Tourettes syndrome: causal relationship between Magnesium deficiency, altered biochemical pathways and symptoms relating to Tourette's syndrome and several reported comorbid conditions. Med Hypotheses. 2002; 58(1):47-60.

77. Wells IC. Evidence that the etiology of the syndrome containing type 2 diabetes results from abnormal magnesium metabolism. Can J Physiol Pharm. 2008;86(1-2):16-24.

78. Wells IC, Agrawal DK, Anderson RJ. Abnormal magnesium metabolism in etiology of salt-sensitive hypertension and type 2 diabetes mellitus. Biol Trace Elem Res. 2004;98(2):97-108.

79. Berry GT, Buccafusca R, Greer JJ, Eccleston E. Phosphoinositide deficiency due to inositol depletion is not a mechanism of lithium action in brain. Mol Genet Metab. 2004;82(1):87-92.

80. Flatman PW. Magnesium transport across cell membranes. J Membr Biol. 1984;80:1-14.

81. Vespa P, Bergsneider M, Hattori N, et al. Metabolic crisis without brain ischemia is common after traumatic brain injury: a combined microdialysis and positron emission tomography study. J Cereb Blood Flow Metab. 2005;25(6):763-774.

82. Werner C, Engelhard K. Pathophysiology of traumatic brain injury. Br J Anaesth. 2007;99(1):4-9.

83. Dash PK, Johnson D, Clark J, et al. Involvement of the glycogen synthase kinase-3 signalling pathway in TBI pathology and neurocognitive outcome. PloS One. 2011;6(9):e24648.

84. Vincent MF, Van den Berghe G, Hers HG. Increase in phosphoribosyl pyrophosphate induced by ATP and Pi depletion in hepatocytes. FASEB J. 1989;3:1862-1867.

85. Vincent MF, Van den Berghe G, Hers HG. D-xylulose-induced depletion of ATP and Pi in isolated rat hepatocytes. FASEB J. 1989;3: 1855-1861

86. Gadd REA, Henderson JF. Studies of the binding of phosphoribosyl pyrophosphate to adenine phosphoribosyltransferase. $J$ Biol Chem. 1970;245(11):2979-2984.

87. Des Rosiers C, Lalanne M, Willemot J. Effects of glycerol and fructose on purine synthesis de novo and on PP-ribose-P availability in rat liver cells. Can J Biochem. 1982;60:1109-1115.

88. Kleinedam A, Vavassori S, Wang K, Schweizer LM, Griac P, Schweizer LM. Valproic acid- and lithium-sensitivity in prs mutants of Saccharomyces cerevisiae. Biochem Soc Trans. 2009;37:1115-1120.

89. Wilson MS, Livermore TM, Saiardi A. Inositol pyrophosphates: between signaling and metabolism. Biochem J. 2013;452(3):369-379.

90. Zimmer HG. Significance of the 5-phosphoribosyl-1-pyrophosphate pool for cardiac purine and pyrimidine nucleotide synthesis: studies with ribose, adenine, inosine and orotic acid in rats. Cardiovasc Drugs Ther. 1988;12(suppl 2):179-187.

91. Becker MA, Raivio KO, Seegmiler JE. Synthesis of ribosyl pyrophosphate in mammalian cells. Adv Enzymol Related Areas Mol Biol. 1979;49:281-306.

92. Leprivier G, Remke M, Rotblat B, et al. The eEF2 kinase confers resistance to nutrient deprivation by blocking translation elongation. Cell. 2013;153(5):1064-1079.

93. Maes M, Leonard BE, Myint AM, Kubera M, Verkerk R. The new 5-HT hypothesis of depression. Prog Neuropsychoparmacol Biol Psychiatry. 2011;35(3):702-721.

94. Fatokun AA, Stone TW, Smith RA. Oxidative stress in neurodegeneration and available means of protection. Front Biosci. 2008;13:3288-3311.

95. Essa MM, Subash S, Braidy N, et al. Role of NAD+, oxidative stress, and tryptophan metabolism in autism spectrum disorders. Int J Tryptophan Res. 2013;6(suppl 1):15.

96. Klaidman L, Morales M, Kem S, Yang J, Chang ML, Adams JD Jr. Nicotinamide offers multiple protective mechanisms in stroke as a precursor for NAD+, as a PARP inhibitor and by partial restoration of mitochondrial function. Pharmacology. 2003;69(3):150-157.

97. Zhang T, Kraus L. SIRT-1 dependent regulation of chromatin and transcription: linking NAD+ metabolism and signalling to the control of cellular functions. Bioch Biphys Acta. 2010;1804(8):1666-1675.
98. Feldblum S, Rougier A, Loiseau H, et al. Quinolinic-phosphoribosyl transferase activity is decreased in epileptic human brain tissue. Epilepsia. 1988;29(5):523-529.

99. Delahunty TM. Mild traumatic brain injury enhances muscarinic receptor-linked inositol phosphate production in rat hippocampus. Brain Res. 1992;594:307-310.

100. Van Calker D, Biber K, Walden J, Gebicke P, Berger M. Carbamazepine and adenosine receptors. In: Manji HK, Bowden C, Belmaker R, editors. Bipolar Medications: Mechanisms of Action. (Chap. 14). Washington, DC: American Psychiatric Association; 2000: 331-345.

101. Gilad GM, Gilad VH. Novel polyamine derivatives as neuroprotective agents. J Pharmacol Exp Therp. 1999;291(1):39-43.

102. Gilad GM, Gilad VH. Polyamines in neurotrauma. Ubiquitous molecules in search of a function. Biochem Pharmacol. 1992;44(3): 401-407.

103. Lightfoot HL, Hall J. Endogenous polyamine function, the RNA perspective. Nucl Acids Res. 2014;42(18):11275-11290.

104. Visvanathan A, Ahmed K, Even-Faitelson L, Lleres D, Bazett-Jones DP, Lamond AI. Modulation of higher order chromatin conformation in mammalian cell nuclei can be mediated by polyamines and divalent cations. PLoS One. 2013;8(6):e67689.

105. Grilley D, Soto AM, Draper D. Direct quantitation of $\mathrm{Mg}^{++}$-RNA interactions by use of a fluorescent dye. Methods Enzymol. 2009; 455:71-91.

106. Sherman WR, Leavitt AL, Honchar MP, Hallcher LM, Phillips BE. Effect of lithium on phosphoinositides. Evidence that lithium alters phosphoinositide metabolism: chronic administration elevates primarily D-myo-inositol-1-phosphate in cerebral cortex of the rat. J Neurochem. 1981;36(6):1947-1951.

107. Piron J, Chveau FS, Amarouch MY, et al. KCNE1-KCNQ1 osmoregulation by interaction of PIP2 with $\mathrm{Mg}^{++}$and polyamines. $J$ Physiol. 2010;588(pt18):3471-3483.

108. Vespa PM, McArthur D, O'Phelan K, et al. Persistently low glucose correlates with poor outcome 6 months after human traumatic brain injury despite a lack of increased lactate: a microdialysis study. J Cereb Blood Flow Metab. 2003;23(7):865-877.

109. Otori T, Friedland JC, Simson G, McIntosh TK, Raghupathi R, Welsh FA. Traumatic brain injury elevates glycogen and induces tolerance to ischemia in rat brain. J Neurotrauma. 2004;21(6):707-718.

110. Shimon AG. Human evidence of the role of inositol in bipolar disorder and antibipolar treatment. In: Manji HK, et al., editors. Bipolar Medications Mechanism of Action. (Chap. 2). Washington, DC: American Psychiatric Association; 2000:31-45.

111. Temkin NR, Anderson GD, Winn HR, et al. Magnesium sulfate for neuroprotection after traumatic brain injury: a randomised controlled trial. Lancet Neurol. 2007;6(1):29-38.

112. Nicoletti F, Wroblewski JT, Costa E. Magnesium ions inhibit the stimulation of inositol phospholipid hydrolysis by exogenous excitatory amino acids in primary cultures of cerebellar granule cells. J Neurochem. 1987;8(3):967-973.

113. Yu F, Wang Z, Tchantchou F, Chin CT, Zhang Y, Chuang DM. Lithium ameliorates neurodegeneration, suppresses neuroinflammation and improves behavioural performance in a mouse model of traumatic brain injury. J Neurotrauma. 2012;29:362-374.

114. Allen PJ, D'Anci KE, Kanarek RB, Renshaw PF. Chronic creatine supplementation alters depression-like behaviour in rodents in a sex-dependent manner. Neuropsychopharmacology. 2010;35(2): 534-546.

115. Regenold WT, Phatak P, Marano CM, Sassan A, Conley RR, Kling MA. Elevated cerebrospinal fluid lactate concentrations in patients with bipolar disorder and schizophrenia: implications for the mitochondrial dysfunction hypothesis. Biol Psychiatry. 2009;65:489-494.

116. Kato T, Kato N. Mitochondrial function in bipolar disorder. Bipolar Disord. 2000;2(3 pt 1):180-190.

117. Young LT. Is bipolar a mitochondrial disease? J Psychiatry Neurosci. 2007;32(3):160-161. 
118. Berge D, Salgado P, Rodrioguez A, Bulbena A. Onset of mania after CPAP in a man with obstructive sleep apnea. Psychosomatics. 2008;49(5):447-449.

119. Sharafkhaneh A, Giray N, Richardson P, Young T, Hirshkowitz M. Association of psychiatric disorders and sleep apnea in a large cohort. Sleep. 2005;28(11):1405-1411.

120. Sugano T, Nishimura K, Soyabe N, et al. Availability of Pi affects mitochondrial $\mathrm{Mg}^{++}$concentrations. Arch Biochem Biophy. 2002;264: 144-154.

121. Martin DS, Bertino JR, Koutcher JA. ATP depletion can markedly enhance cancer therapy: fresh insight for a new approach. Cancer Res. 2000;60:6776-6783.

122. Gomes AP, Price NL, Ling AJ, et al. Decline in NAD (+) induces a pseudo-hypoxic state disrupting nuclear-mitochondrial communication during aging. Cell. 2013;155(7):1624-1638.

123. Stein LR, Imai S. The dynamic regulation of NAD metabolism in mitochondria. Trends Endocrinol Metab. 2012;23:420-428.

124. Gitzelman R. Galactose-1-phosphate in the pathophysiology of galactosemia. Eur J Pediatr. 1995;154:S53-S64.

125. Maddock RJ, Moses JA Jr, Roth WT, King R, Murchison A, Berger PA Serum phosphate and anxiety in major depression. Psychiatry Res. 1987;22(1):29-36.

126. Johnson MA, Tekkanat K, Schmaltz SP, Fox IH. Adenosine triphosphate turnover in humans. Decreased degradation during relative hyperphosphatemia. J Clin Invest. 1989;84:990-995.

127. Runnels LW, Yue L, Chapham DE. The TRPM7 channel is inactivated by PIP(2) hydrolysis. Nat Cell Biol. 2002;4:329-336.

128. Aarts MM, Tymianski M. TRPM7 and ischemic CNS injury. Neuroscientist. 2005;11(2):116-123.

129. Langeslag M, Clark K, Moolenar WH, van Leewen FN, Jalink K Activation of TRPM7 channels by Phospholipase C coupled receptor agonists. J Biol Chem. 2007;282:232-239.

130. Romani AM. Cellular magnesium homeostasis. Arch Biochem Biophys. 2011;512(1):1-23.

131. Nicotera P, Bellomo G, Orrenius S. The role of $\mathrm{Ca} 2+$ in cell killing. Chem Res Toxicol. 1990;3:484-494.

132. Aarts M, Iihara K, Wei WL, et al. A key role for TRPM7 channels in anoxic neuronal death. Cell. 2003;115(7):863-877.

133. Inoui K, Branigan D, Xiong Z-G. Zinc-induced neurotoxicity mediated by transient receptor potential melastatin 7 channels. J Biol Chem. 2010;285(10):7430-7439.

134. Muto J, Lee H, Lee H, et al. Oral administration of inosine produces antidepressant-like effects in mice. Sci Rep. 2014;4:4199.

135. Yang C, Zhou ZQ, Gao ZQ, Shi JY, Yang JJ. Acute increases in plasma mammalian target of rapamycin, glycogen synthase kinase- 3 beta, and eukaryotic elongation factor 2 phosphorylation after ketamine treatment in three depressed patients. Biol Psychiatry. 2013;73:e35-e36.

136. Ha HC, Snyder SH. Poly (ADP-ribose) polymerase-1 is a mediator of necrotic cell death by ATP depletion. PNAS. 1999;96(24) $13978-13982$.

137. Toledano E, Ogryzko V, Danchin A, Ladant D, Mechold U. 3'-5' phosphoadenosine phosphate is an inhibitor of PARP-1 and a potential mediator of the Lithium dependent inhibition of PARP-1 in vivo. Biochem J. 2012;443(2):485-490.

138. Kim MY. Regulation of chromatin structure by PARP-1. Methods $\mathrm{Mol}$ Biol. 2011;780:227-236.

139. Castro CE. Nutrient effects on DNA and chromatin structure. Ann Rev Nutr. 1987;7:407-421.

140. Essa MM, Subash S, Braidy N, et al. Role of NAD+, oxidative stress, and tryptophan metabolism in autism spectrum disorders. Int J Tryptophan Res. 2013;6(suppl 1):15-28.

141. Li C, Fen JJ, Wu YP, Zhang GY. Cerebral-reperfusion induces GAPDH S-nitrosylation and nuclear translocation. Biochemistry (Mosc). 2012;77:671-678.

142. Phiel CJ, Zhang F, Huang EY, Guenther MG, Lazar MA, Klein PS. Histone deacetylase is a direct target of valproic acid, a potent anticonvulsant, mood stabilizer, and teratogen. J Biol Chem. 2001;276:36734-36741.
143. Sauve AA. NAD+ and vitamin B3: from metabolism to therapies. J Pharmacol Exp Ther. 2008;324:888-893.

144. Canto C, Sauve AA, Bai P. Crosstalk between poly (ADP-ribose) polymerase and Sirtuin enzymes. Mol Aspects Med. 2013;34(6): 1168-1201.

145. Luna A, Aladjem MI, Kohn KW. SIT1/Parp1 crosstalk: connecting DNA damage and metabolism. Genom Integ. 2013;4:6.

146. Galli M, Van Gool F, Rongvaux A, Andris F, Leo O. The nicotinamide phosphotransferase; a molecular link between metabolism, inflammation, and cancer. Cancer Res. 2010;70(1):8-11.

147. Zhang T, Berrocal JG, Frizell KM, et al. Enzymes in the NAD salvage pathway regulate SIRT1 activity at target gene promoters. J Biol Chem. 2009;284(30):20408-20417.

148. Hearl WG, Chuchich JE. A mitochondrial NADP+ dependent reductase related to the 4-aminobutyrate shunt. Purification, characterization and mechanism. J Biol Chem. 1985;260:16361-16366.

149. Mamalek M. Gammahydroxybutyrate: an endogenous regulator of energy metabolism. Neurosci Biobehav Rev. 1989;13(4):187-198.

150. Loscher W. Basic pharmacology of valproate; a review after 35 years of clinical use for the treatment of epilepsy. CNS Drugs. 2002; 16(10):669-694.

151. zur Nedden A, Doney AS, Frenguelli BG. Modulation of intracellular ATP determines adenosine release and functional outcome in response to metabolic stress in rat hippocampus slices and cerebellar granule cells. J Neurochem. 2014;1:111-124.

152. Haile CN, Murrough JW, Iosifescu DV, et al. Plasma brain derived neurotrophic factor (BDNF) and response to ketamine in treatment-resistant depression. Int $J$ Neuropsychopharmacol. 2014;17(2):331-336.

153. Tallman JF, Paul SM, Skolnick P, Gallager DW. Receptors for the age of anxiety: pharmacology of the benzodiazepines. Science. 1980; 207:274-281.

154. Dash PK, Orsi SA, Zhang M, et al. Valproate administered after traumatic brain injury provides neuroprotection and improves cognitive function in rats. PLoS One. 2010;5(6):e11383.

155. Shibata K, Kondo R, Sano M, Fukuwatari T. Increased conversion of tryptophan to nicotinamide in rats by dietary valproate. Biosci Biotechnol Biochem. 2013;77(2):295-300.

156. Maciejak P, Szyndler J, Turzyńska D, et al. The kynurenine pathway: a missing piece in the puzzle of valproate action? Neuroscience. 2013;234:135-145.

157. Chang P, Terbach N, Plant N, Chen PE, Walker MC, Williams R. Seizure control by ketogenic diet-associated medium chain fatty acids. Neuropharmacology. 2013;69:105-114.

158. Salvadore G, Viale CI, Luckenbaugh DA, et al. Increased uric acid levels in drug-naïve subjects with bipolar disorder during a first manic episode. Prog Neuropsychopharmacol Biol Psychiatry. 2010;34(6):819-821.

159. Masino SA, Kawamura M, Wasser CD, Pomeroy LT, Ruskin DN. Adenosine, ketogenic diet and epilepsy: the emerging therapeutic relationship between metabolism and brain activity. Curr Neuropharmacol. 2009; 7:257-268.

160. Van Calker D, Biber K, Walden J, Gebicke P, Berger M. Carbamazepine and adenosine receptors. In: Manji HK, et al., editors. Bipolar Medications Mechanism of Action. Washington, DC: American Psychiatric Association; 2000:331-345.

161. Mork A, Jensen JB. Effects of lithium and other mood stabilizing agents on the cyclic adenosine monophosphate signaling system in the Brain. In: Manji HK, et al., editors. Bipolar Medications Mechanism of Action. Washington, DC: American Psychiatric Association; 2000:109-128.

162. Mann L, Heidmann E, Berdsudsky Y, et al. Inhibition of specific adenylyl cyclase isoforms by lithium and carbamazepine, but not valproate, may be related to their antidepressant effect. Bipolar Disord. 2009;11(8):885-896.

163. Romani AMP. Intracellular magnesium homeostasis. In: Vink R, Nechifor M, editors. Magnesium in the Central Nervous System. (Chap. 2). Adelaide, SA: University of Adelaide Press; 2011:13-59. 
164. Nechifor M. Magnesium in psychoses (schizophrenia and bipolar). In: Vink R, Nechifor M, editors. Magnesium in the Nervous System. (Chap. 22). Adelaide, SA: University of Adelaide Press; 2011:303-311.

165. Liu J, Hirai K, Litt L. Fructose-1,6-Biphosphate does not preserve ATP in hypoxic-ischaemic neonatal cerebrocortical slices. Brain Res. 2008;1238:230-238.

166. Kelleher JA, Chan PH, Chan TYY, Gregory GA. Energy metabolism in hypoxic astrocytes: protective mechanism of fructose-1,6-biphosphate. Neurochem Res. 1995;20:785-792.

167. Lian XY, Khan FA, Stringer JL. Fructose-1,6-bisulphosphate has anticonvulsant activity in models of acute seizure in adult rats. J Neuroscience. 2007;27(44):12007-12011.

168. Alva N, Carbonell T, Roig T, Bermudez J, Polomeque J. Fructose-16-biphosphate administration to rats prevents metabolic acidosis and oxidative stress induced by deep hypothermia and rewarming. Eur $J$ Pharmacol. 2011;659:259-264.

169. Vexler ZS, Wong A, Francisco C, et al. Fructose-1,6-bisphosphate preserves intracellular glutathione and protects cortical neurons against oxidative stress. Brain Res. 2003;960(1-2):90-98.
170. Roig T, Bartrons R, Bermudez J. Exogenous fructose-1,6-diphosphate reduces $\mathrm{K}+$ permeability in isolated rat hepatocytes. Am J Physiol Cell Physiol. 1997;273:C473-C478.

171. Mirhashemi SM, Aarabi MH. To study various concentrations of Mg and Al on Amylin conformation. Pak J Biol Sci. 2011;14(11):653-657.

172. Sarkar S, Floto RA, Berger Z, et al. Lithium induces autophagy by inhibiting inositol monophosphatase. J Cell Biol. 2005;170:1101-1111.

173. Levine J, Barak Y, Gonsalves M, et al. A double-blind controlled trial of inositol treatment of depression. Am J Psych. 1995;152:792-794.

174. Nowak L, Bregestovski P, Ascher P, Herbet A, Prochiantz A. Magnesium gates glutamate-activated channels in mouse central neurones. Nature. 1984;307:462-465.

175. Rosanoff, A, Seelig MS. Comparison of mechanism and functional effects of magnesium and statin pharmaceuticals. J Am Coll Nutr. 2004;23(5):501S-505S.

\section{Publish your work in this journal}

Neuropsychiatric Disease and Treatment is an international, peerreviewed journal of clinical therapeutics and pharmacology focusing on concise rapid reporting of clinical or pre-clinical studies on a range of neuropsychiatric and neurological disorders. This journal is indexed on PubMed Central, the 'PsycINFO' database and CAS, and is the official journal of The International Neuropsychiatric Association (INA). The manuscript management system is completely online and includes a very quick and fair peer-review system, which is all easy to use. Visit http://www.dovepress.com/testimonials.php to read real quotes from published authors.

Submit your manuscript here: http://www.dovepress.com/neuropsychiatric-disease-and-treatment-journal 